\title{
Changing Tides: \\ An Exploration of Time and Place
}

\author{
by
}

Wendy Richards

A thesis submitted to the Faculty of Graduate and Postdoctoral Affairs in partial fulfillment of the requirements for the degree of

\author{
Master of Architecture \\ Carleton University \\ Ottawa, Ontario
}

(C) 2017, Wendy Richards 


\section{ABSTRACT}

This thesis explores ways in which the built environment contributes to collective memory and informs a sense of place within the cultural landscape of Moncton, New Brunswick. The intention is to respond to the current changes in the landscape from a cultural perspective as the city attempts to remedy environmental and ecological issues that have transpired as a result of human intervention.

By preserving the infrastructure that contributed to the current conditions of the site, while integrating new architectural elements, the proposal draws awareness to the history of the site, celebrates the identity of the place, and encourages a new perspective on the changing landscape. Through this, new spaces for cultural activities emerge to re-establish a lost connection between the city and the river. 


\section{ACKNOWLEDGMENTS}

I would like to express my gratitude to my advisor, Yvan

Cazabon, for the guidance, encouragement and inspiration

offered throughout the past year, as well as for prompting me to appreciate my hometown in a new light.

I want to thank my sister for being a constant inspiration with her contagious positive energy and ambition, my father for his support and encouragement throughout my education, and my grandparents for making this journey possible. Most importantly, I would like to thank my mother for her continued love, abundant patience and endless support. I am forever grateful.

To my friends who have been there for support and laughter along the way, no matter the distance - thank you. 


\section{CONTENTS}

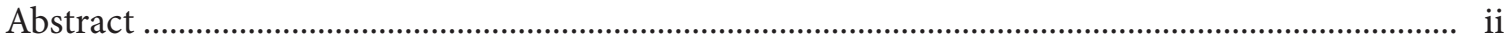

Acknowledgments ......................................................................................................................... iii

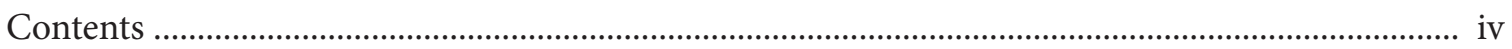

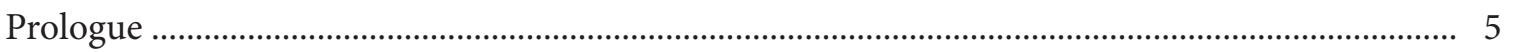

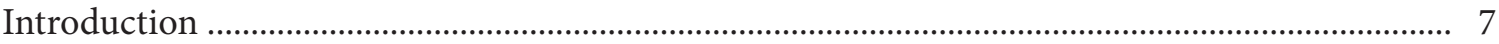

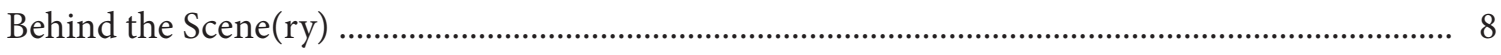

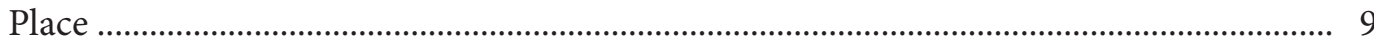

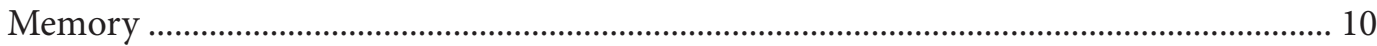

Cultural Landscapes .......................................................................................................... 13

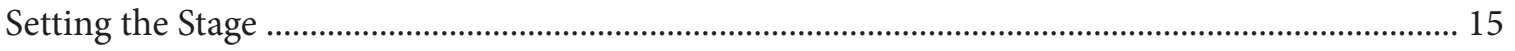

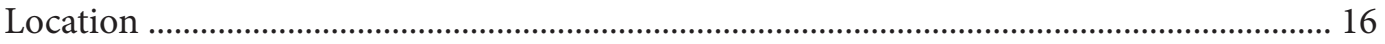

Along the River in Moncton, New Brunswick ………………............................................ 18

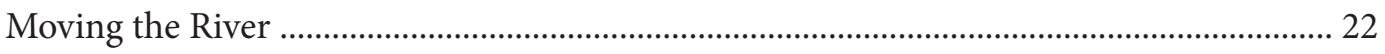

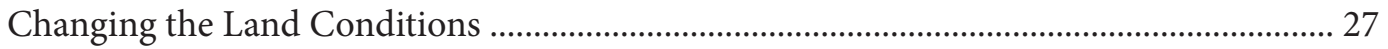

Bring the River Back a Bit to the Right. ................................................................................. 29

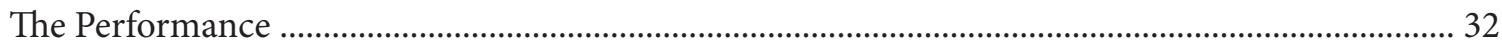

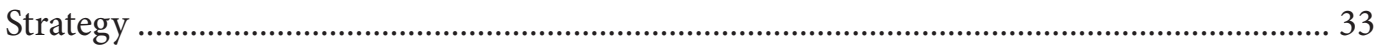

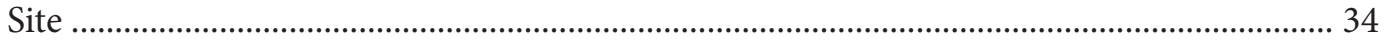

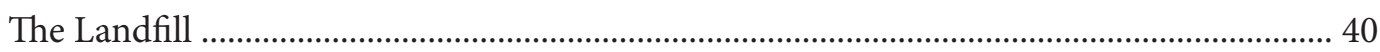

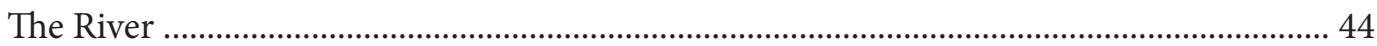

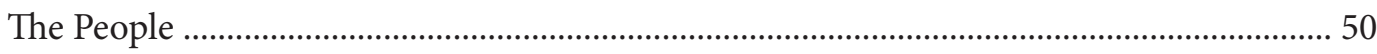

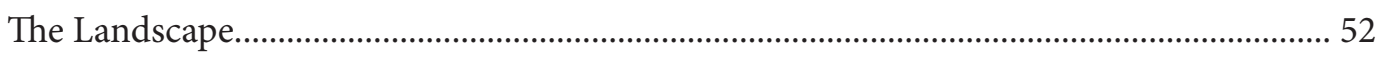

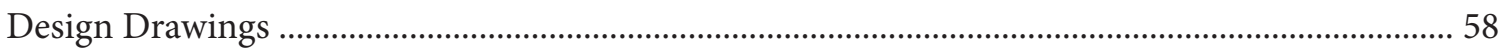

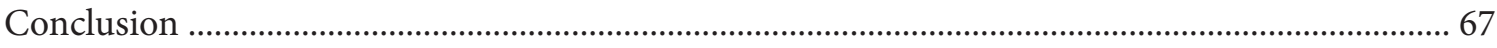

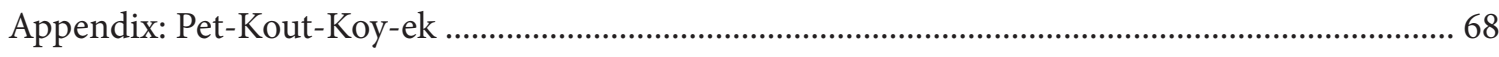

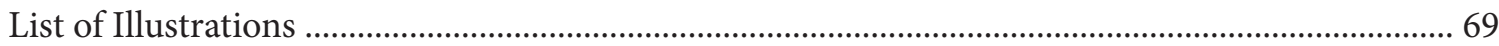

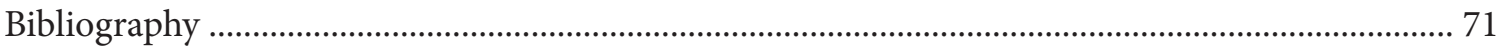




\section{PROLOGUE}

When I think of home, flashes of moving pictures appear in my mind like a series of film segments. They would seem to appear in no particular order to anyone else. The first scene finds me on the trail along the river where I used to jog and take lazy walks with a friend. But like a film, it is more than merely an image. I can sense the long marsh grass fluttering in the openness and the speed of the chocolate colored water flowing alongside, rushing through as the tide moves in. The sudden wind gusts bend the grass over completely to reveal the extent of the muddy silt deposits of the riverbank. The picture stretches from my mind to my skin, triggering the familiar sense of the open marsh wind. It brings with it a particular scent and freshness, while pushing me slightly off balance as I'm the tallest standing element on the marsh. I catch myself taking a deep breath, trying to take in the familiar coastal air that's playing in my mind, as my body remains in a different city where humidity hangs between the buildings.

The image switches to people talking on Main Street, the central axis of the city. They didn't intend to stop there but they continue the chatter, as if they've forgotten their destination and time waits for them to catch up with the familiar passerby. The

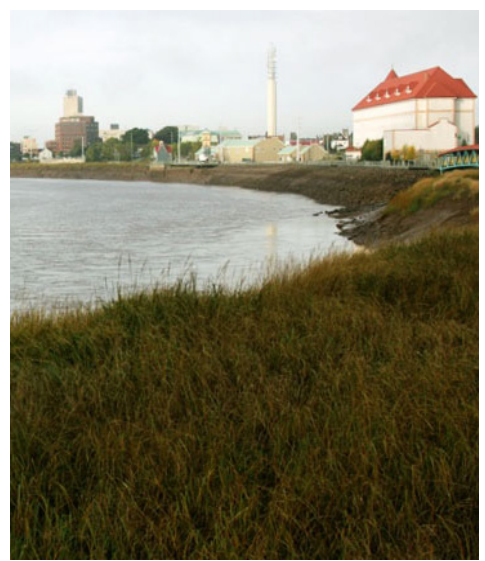

Figure 1. Petitcodiac River edge

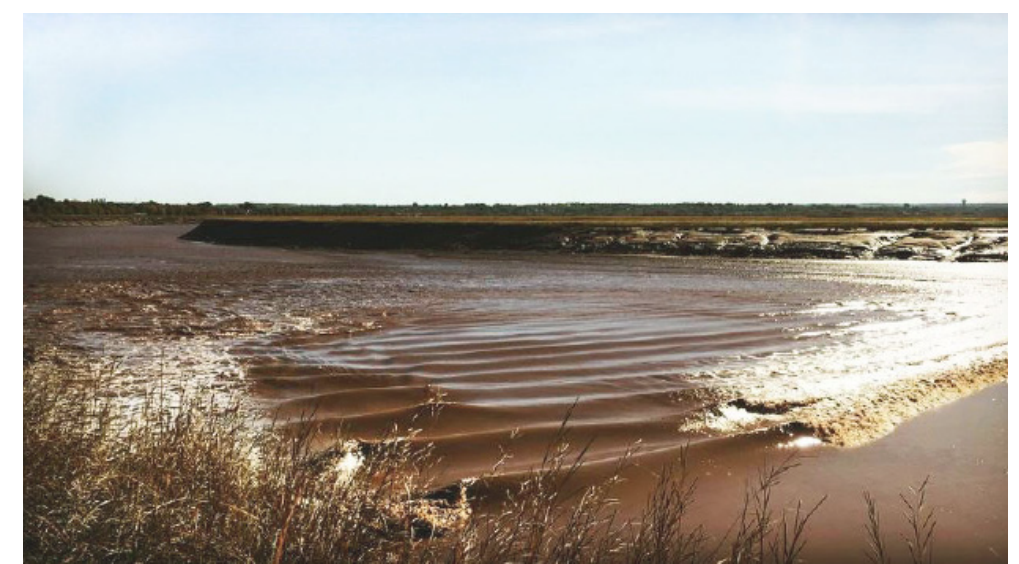

Figure 2. Petitcodiac River 
lightheartedness and friendliness in their body language lightens my mood. As they step aside on the uneven brick sidewalk and nod to the passing jogger who gives a 'thank you' wave back, a stranger in the background with a coffee-to-go holds the nearby café door open for two friends. They smile and nod without breaking conversation, speaking informally between two languages, and enter the low, weathered brick building. Who are these people? A projection from my typical experiences of home, I suppose. What a lovely place my mind has recreated! The political conflicts and job scarcity escape me. I don't sense those variables from here, and nor when I'm there. Those are known factors, but they take conversational triggers for my mind to recall. As the film segments continue, I realize they become less of an experience and more of a still image, until eventually they're merely ideas drifting past.

The strength of familiarity as well as the complexity of the sensory experience associated to the memories seem to determine the order in which they flash in my mind. The initial, more detailed scenes allow me to experience the memory rather than simply recall it, giving the place a presence in my mind. They relocate my senses from one place into a projection of another place, creating the feeling of home.

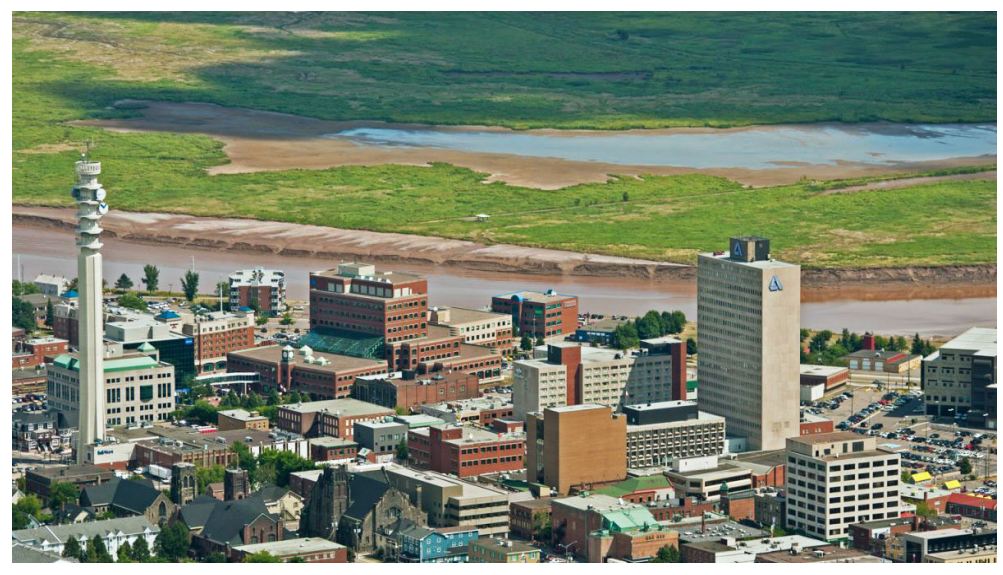

Figure 3. Aerial view of downtown Moncton

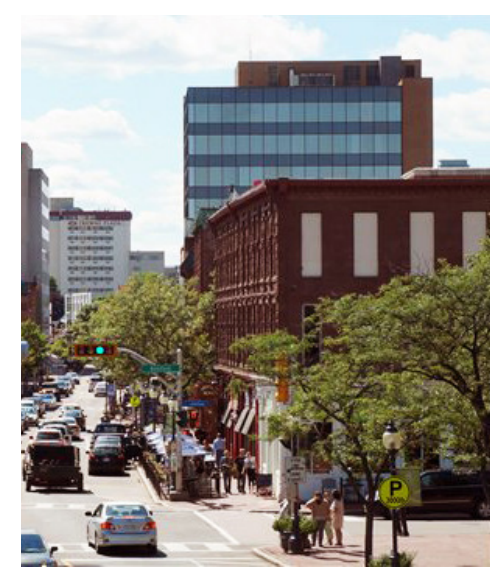

Figure 4. Main Street, Moncton 


\section{INTRODUCTION}

Every place holds a unique identity, constructed as a perceived web of relationships that exists between the features, characteristics and conditions of the site. The mere fact that things exist in the same space creates an initial interaction between them by way of being recognized as parts of a larger whole. As we engage with and build on a site, specific relationships are strengthened through associations while new, and sometimes unexpected ones, are formed.

We both create and decode these relationships along our journey through a space, realized as both physical movement through space as well as a sensory journey within space. The development of the journey allows the previous element to relate to the next through sequential memory, and as the physical and sensory memories are layered, the relationship web continues to grow increasingly intricate.

Every place also has a history. Even young cities that may not have old buildings retain a long history embedded in the land itself. As the space persists through time, the past life of the site interacts with itself in the present, adding yet another dimension to be discovered along our journey through the space, and further developing the identity of the place. 
Behind the Scene(ry)

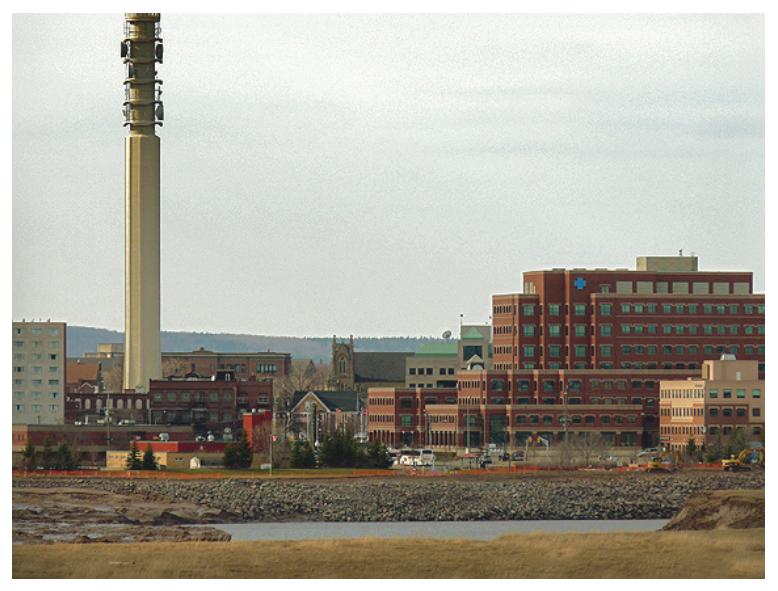

Figure 5. View of Moncton from Riverview 


\section{Place}

To convey the experience of a place requires the inclusion of both tangible and intangible characteristics, describing not only the physical features of an area, but also the distinctive feelings and associations attached to the space - how we experience, express and imagine the elements of that space. In architecture, the word place is associated with the genius loci. This is a term often used to convey the perceived presence of a unique and physical place and is classically derived from the protective spirit of that place. ${ }^{1}$

\footnotetext{
"Genius loci cannot be designed to order. It has to evolve, to be allowed to happen, to grow and change from the direct efforts of those who live and work in places and care about them. [...The] understanding of others' lives and problems will always be partial. Just as outsiders cannot feel their pain, so they cannot experience their sense of place."2
}

With increased familiarity to a place, our understanding and attachment, and therefore sense of belonging, also increases. Norberg-Schulz calls place a space where humans know their presence. ${ }^{3}$ In this sense, place is seen as an awareness of our identity and of the relationship we have to our known physical and cultural environment.

The concept 'sense of place' attempts to describe the complex and emotional relationship we develop with a place and can be defined as a "mental appreciation of environment and the creation of feeling among the viewers in relation to the

\footnotetext{
${ }^{1}$ A. Rossi and P. Eisenman, The Architecture of the City, (Cambridge, Mass, 1982), 103.

${ }^{2}$ S.R. Swaffield, Theory in Landscape Architecture: A Reader, (Philadelphia, University of Pennsylvania Press, 2002), 103.

${ }^{3}$ A.P. Vali and S. Nasekhiyan, 'The Concept and Sense of Place in Architecture from Phenomenological Approach, Indian Journal of Fundamental and Applied Life Sciences vol. 4, S4(2014), 3748.
} 
environment."' ${ }^{\prime \prime}$ In other words, a sense of place is created when we layer emotion, meaning and values onto a space. This process therefore marries the objective and external influences in the environment such as landscape, sound, smell and activity, to subjective experiences such as memories, culture and history.

Thus, representing a collection of values and meanings within a society, a strong sense of place in a community holds an important role in social politics and culture. By integrating user and place, it is thought that the likelihood of users to care for spaces and contribute to social activities increases when a strong sense of place is present. ${ }^{5}$ It is recognized that "individual and collective values influence sense of place and [conversely] sense of place affects individual behavior and social values and attitudes" ${ }^{6}$, demonstrating the complexity as well as the significance this concept holds within society.

\section{Memory}

A sense of place is inherently tied to, and informed by, memory. To recognize the presence of a place requires a dialogue between the experience of the individual within the space, the preceding history of the place, and the knowledge of collective cultural ideas.

As we explore a space, we experience our surroundings as

${ }^{4}$ A.P. Vali and S. Nasekhiyan, 'The Concept and Sense of Place in Architecture from Phenomenological Approach', Indian Journal of Fundamental and Applied Life Sciences vol. 4, S4(2014), 3746.

${ }^{5}$ Mina Najafi, Mustafa Kamal Bin Mohd Shariff. 'The Concept of Place and Sense of Place In Architectural Studies', (2011).

${ }^{6}$ Hashem Hashemnezhad, Ali Akbar Heidari, and Parisa Mohammad Hoseini. "'Sense of Place" and "Place Attachment" (A Comparative Study)'. (2013). 
fragmentations of the whole. Our attention constantly shifts to new sensory stimuli, noticing the change in light, noise, view or the ground beneath our feet. Our emotional responses to these moments are encoded as memories of our experience and, as we progress through the space, the memories link together as a sequence of events - the fragments become connected into an emotional narrative of the journey. Because our attention is selective and predisposed to bias, our individual experience of a shared space is unique and, consequently, so is our individual memory of the place.

Maurice Halbwachs distinguishes between individual memory and collective memory. He explains that the former is composed from the specific experience of each person and bound to place and time, whereas the latter emerges from a group and is inherently tied to society. ${ }^{7}$

Collective memory extends beyond the individual's recollection to include memories of shared experiences and events. As a place evolves, traces of these events are left behind as material or symbolic stories of the past.

"When we read a poem we cover enormous distances with the aid of our mind's eye: we travel by invoking and inventing images of people, things, and places. Our familiarity with things and places greatly enriches our source of images, because even when the thing or place we are trying to imagine is unfamiliar to us, we can make a model of it in our minds, using bits of the things and places we do know to construct that model."

In a manner similar to reading a descriptive poem, as we wander through a space riddled with clues that describe a past life, we

\footnotetext{
${ }^{7}$ M. Halbwachs, The Collective Memory, (1st edn, New York, Harper \& Row, 1980), 51-53.

${ }^{8} \mathrm{M}$. Quantrill, The Environmental Memory: Man and Architecture in the Landscape of Ideas, (Schocken, 1987), xx.
} 
are able to exist in the now while simultaneously traveling into the memories of the past - collapsing time in space. Although collective memory has many manifestations including shared stories, myths, rituals, language etc., the act of reading the artifacts that are recorded in the built environment provides a unique experience as it is a tangible and direct link to the pieces of the past. In The Poetics of Space, Gaston Bachelard expresses that "memories are motionless, and the more securely they are fixed in space, the sounder they are."

Gaining an understanding of the ever-changing relationship we have to the space we inhabit strengthens our individual and collective identity, while also increasing our attachment to the place and our ability to describe its own identity.

\begin{abstract}
"Memory and its collective and social dimension are intimately connected with the way we understand our built environment. Urban and natural landscapes act as reminders of the past and its hidden memories. Collective memories are essential when reconstructing the past in the context of the present: even though different communities will transform and distort the past, they will always maintain some sort of anchor to former episodes, in an attempt to validate their positions." ${ }^{10}$
\end{abstract}

The collective memory of a place is constantly adapting through the addition or removal of elements and ideas that influence the perceptions of that place. Consequently, the sense of place is not static and reflects the multiplicity of the memories, identities and histories that are intertwined with it.

\footnotetext{
${ }^{9}$ G. Bachelard, The Poetics of Space, (Boston, Beacon Press, 1969), 9.

${ }^{10}$ S. Bandyopadhyay and G.G. Montiel, The Territories of Identity: Architecture in the Age of Evolving Globalisation, (New York, Routledge, 2013), 78.
} 


\section{Cultural Landscapes}

Although we may initially think of the built environment as the main canvas for the recorded history and memories of a place, many of our past actions remain within our landscapes as well. Particularly with technological advancements, the effects that human activity has on the landscape can be very apparent. Alternatively, the landscape can also affect the built environment, altering the reality of our visions. The outcome of this interplay between us and nature introduces the concept of cultural landscapes.

Cultural landscapes can be understood as the fusion of built and natural environments which display the evolution of a human society and its interactions with the environment, therefore possessing both spatial and social connotations. In The Morphology of Landscape, Carl Ortwin Sauer proposed the following:

\footnotetext{
"The cultural landscape is fashioned from a natural landscape by a cultural group. Culture is the agent, the natural area is the medium, the cultural landscape is the result."'11
}

The condition creates a complex medium for memory that describes not only how a society interacts within itself, but also it's changing relationship with nature. Our evolving social, political and cultural variables are inscribed into the landscape - as they are into our built environment - since shifts in our values are reflected in our actions, and our actions are reflected in our surroundings. Cultural landscapes therefore illustrate the ideologies of the past while simultaneously acting as an

\footnotetext{
${ }^{11}$ C.O. Sauer, The Morphology of Landscape, (California, University of California Press, 1925), 46.
} 
expression of the current culture.

In The Making of the English Landscape, W.G. Hoskins explains that the "landscape itself, to those who know how to read it aright is the richest historical record we possess." 12 Returning to the journey through space, an important variable in understanding place is therefore the ability to read and interpret the landscape.

"Landscape is not to be defined by itemizing its parts. The parts are subsidiary clues to an integrated image. Landscape is such an image, a construct of the mind and of feeling." ${ }^{13}$

The detail of the 'image' - the art and emotion - that we are able to experience thus lies in the descriptiveness of the landscape.

\footnotetext{
${ }_{12}$ M. Blacksell, Hoskins, W. G. 1955: The Making of the English Landscape', Progress in Human Geography, vol. 29/no. 1, (2005), 95-96.

${ }^{13} \mathrm{Y}$. Tuan, 'Thought and Landscape: The Eye and the Mind's Eye,' in D.W. Meinig, ed., The Interpretation of Ordinary Landscapes, (New York: Oxford University Press, 1979), 89.
} 


\section{Setting the Stage}

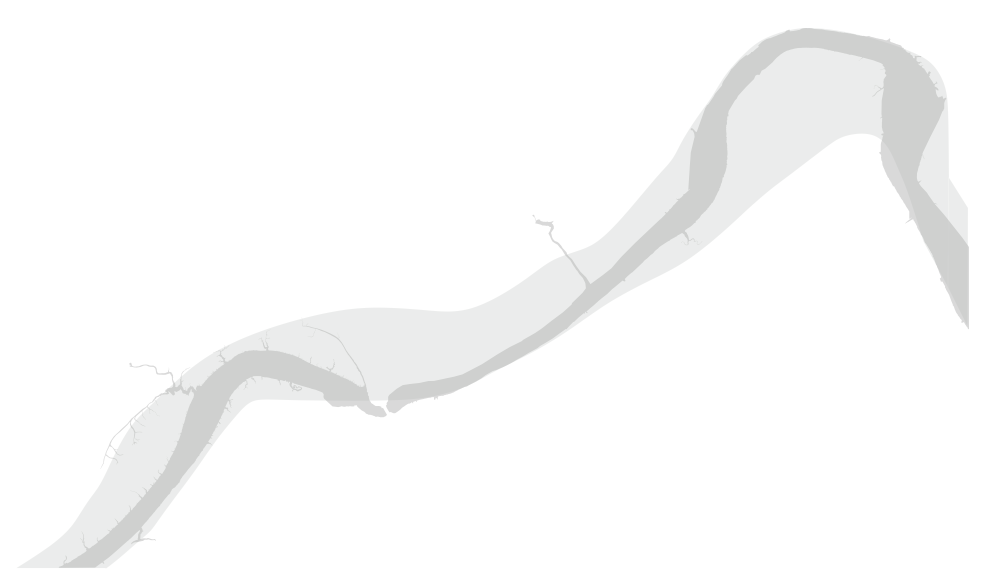

Figure 6: Graphic representation of the change in Petitcodiac River width from 1955 to present 


\section{Location}

The landscape of Moncton, New Brunswick is about to undergo significant changes due to human intervention. However, this is not the first time this has happened; this will be the third major intervention at this specific site. From an open flowing river to a dammed river crossing, and a subsequent landfill site, the area has been heavily manipulated by the human hand and vast repercussions have followed each stage. In recognition and regret of this, the city is in the early stages of removing the dam to reimagine the landscape once again.

In the past 50 years as these events have unfolded, the land has become a strong representation of the evolving culture. By focusing on the cultural landscape, the aim of this project is to achieve a detailed image of not only the history of the land, but the role that the human hand and culture has had in shaping it. Conversely, the reconfiguration of the landscape in the thesis aims to inspire future readings and subsequent actions and histories. 

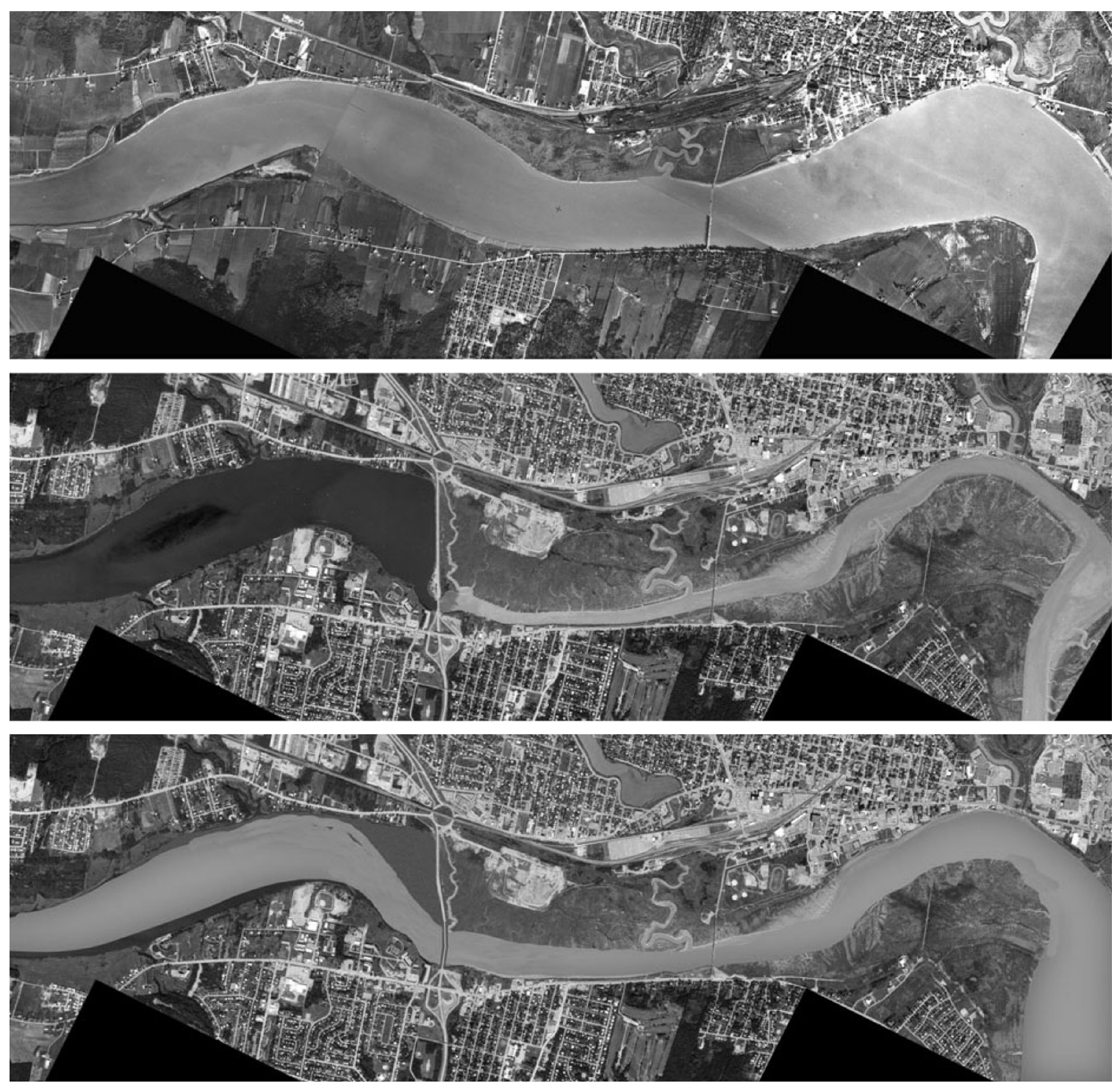

Figure 7: From top to bottom: Aerial view of the landscape in 1955 prior to dam; in 2009; as future projection. 


\section{Along the River in Moncton, New Brunswick}

Located in the southeastern portion of New Brunswick, the city of Moncton is intentionally situated along the banks of the Petitcodiac River. The origin of the river's name can be traced back to the first Mi'kmaq settlers who chose the site for the abundant resources that the river and surrounding land could offer, naming it Epetkutogoyek - translating to the river that bends like a bow.' The dependency and appreciation for the landscape established an immediate - and what would continue to be - a strong relationship between the culture and the land.

The Petitcodiac River connects to the Atlantic Ocean through the Bay of Fundy which experiences the highest tides in the world. The flood tide is fronted by a standing wave that leads the tide up the river, called a tidal bore. The tide slowly changes the water level by nine to fourteen meters, depending on the day. The combination of this extreme tidal range and the upward slope of the river floor is what creates the rare tidal bore phenomenon that reached between one and two meters in height in the past, and is currently seen just below one meter.

The shoreline of the river is composed of vast mudflats and soft sandstone which is easily eroded by the powerful tides and suspended in the water column. The tidal water distributes the enormous amount of suspended sediment up the river, to be returned as the tide recedes. The frequent movement of the sediment is what inspired the river's unique nickname - The Chocolate River - due to the resulting brown murky color of the water. 


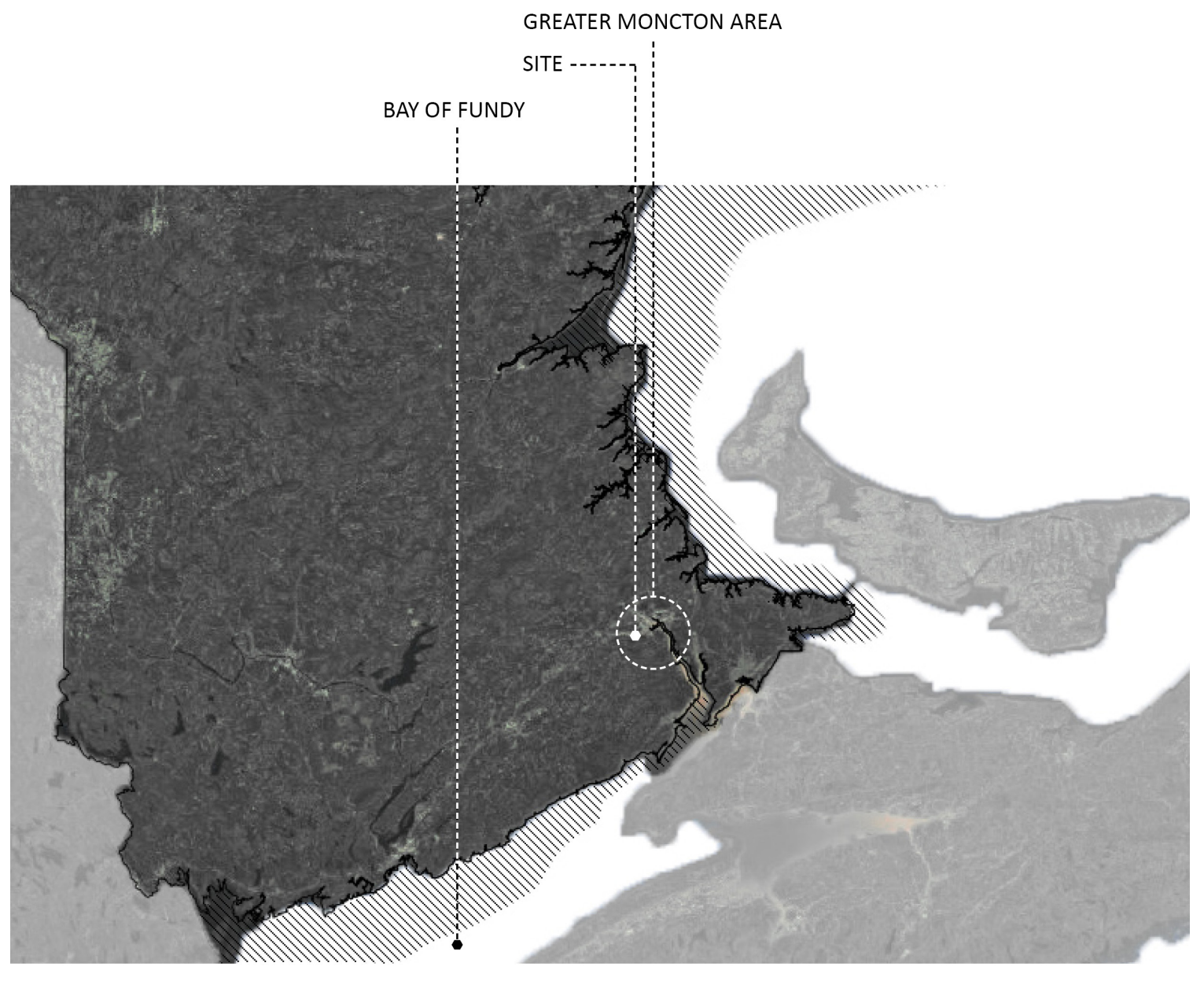

Figure 8: Map of New Brunswick 


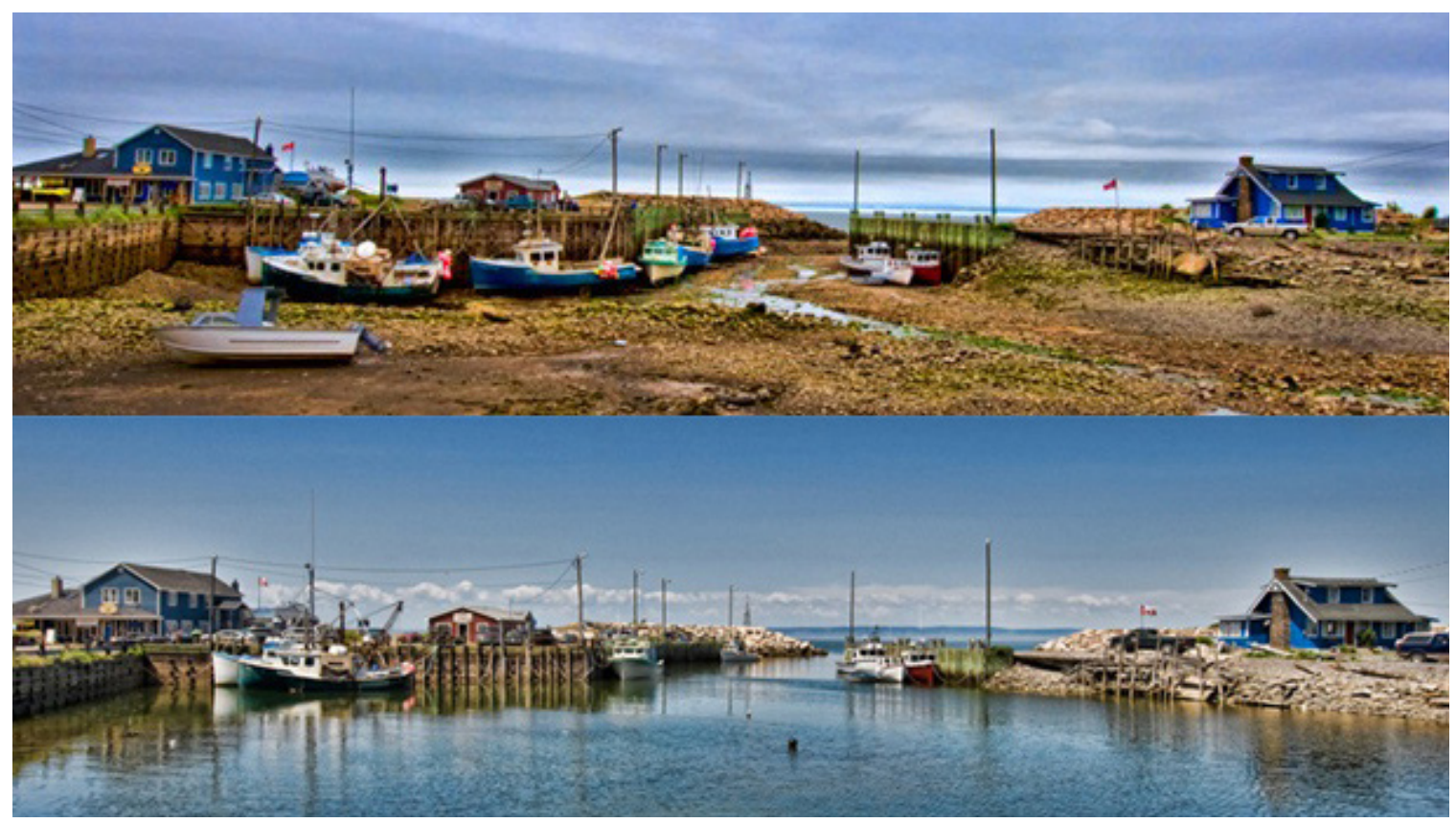

Figure 9: Comparison of high and low tide in the Bay of Fundy

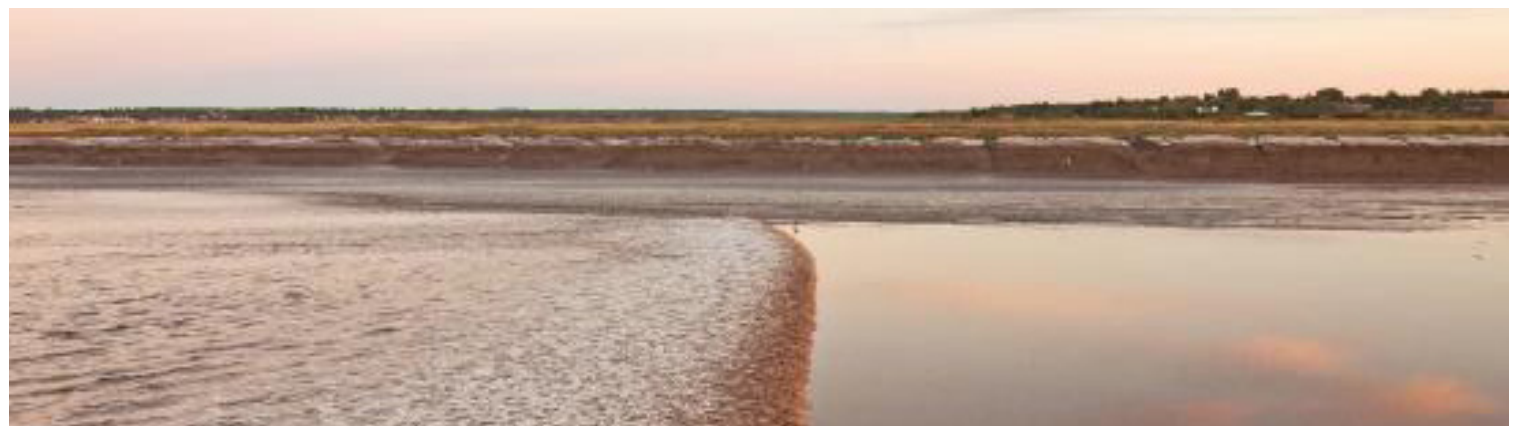

Figure 10: Tidal bore in Petitcodiac River

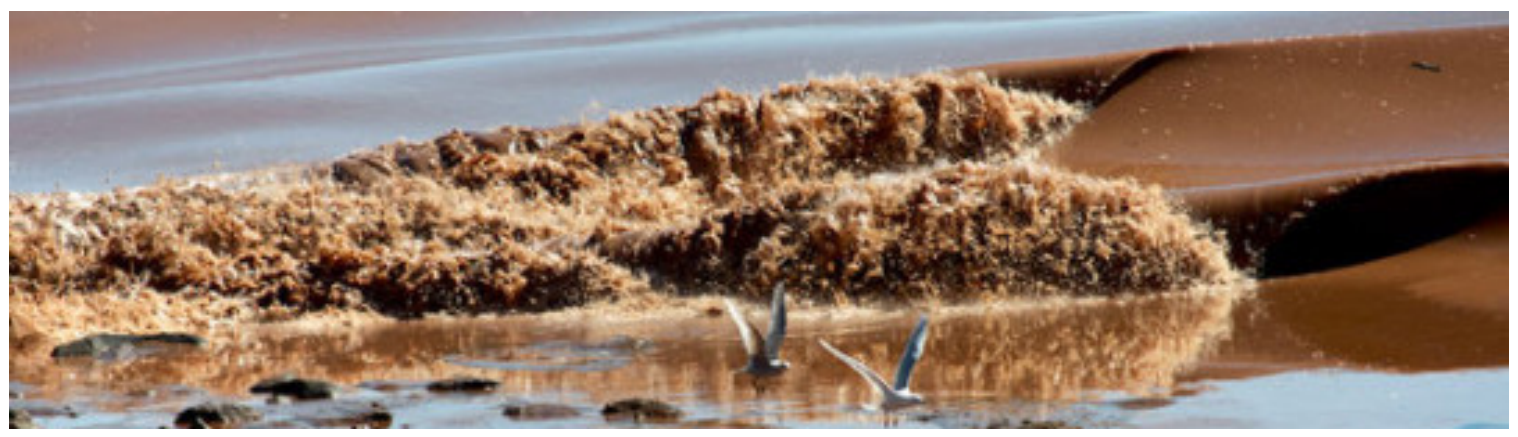

Figure 11: Tidal bore in Petitcodiac River 


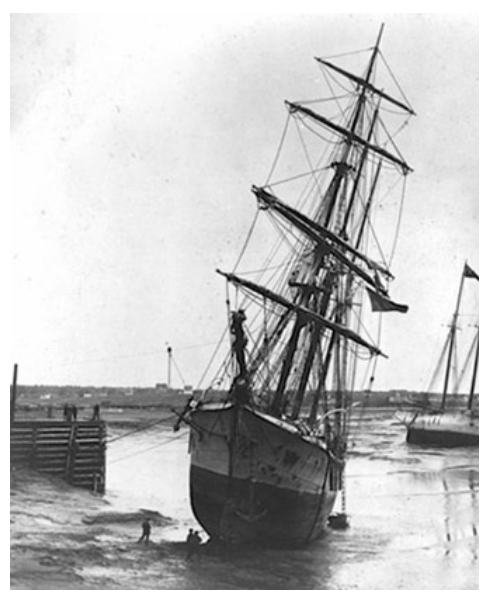

Figure 12: Shipbuilding in Moncton in early 1800's

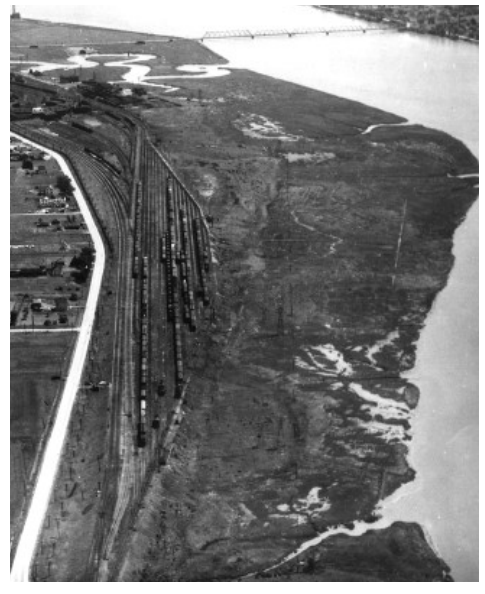

Figure 13: Aerial view of rail system in Moncton 1880
The banks of the river and surrounding marshlands are rich in nutrients and served as an important resource for early settlers. The marshlands were diked by Acadian settlers to grow crops of wheat along the banks of the fertile river, while Spartina and Eelgrass were harvested from the salt marshes to be used as hay and insulation in homes. ${ }^{14}$ The water itself also housed an important dietary resource with the abundant species of fish. In addition to the more tangible resources the river offered, it also provided easy transportation within the area and between communities. The landscape was therefore an integral part of life and anchored the early communities both geographically and culturally.

Changes to both society and local culture directly influenced the site over time. The riverbanks became littered with wharves as Moncton developed into a shipbuilding hub in the early to mid 1800 's. Movement on the river also increased as the city's timber exportation and commercial fishing industries flourished.

As Moncton became a small port city, the built environment expanded around, as well as into, the river to accommodate the new shipyard workers and their families. The waterfront remained the anchor and activity of the city - as it was with the first settlers - facilitating more than eight hundred feet of public wharves along the riverbank.

However, as the tides rolled in and out, so did the industries. Like many Canadian cities, the manufacturing and exportation sites along the water were later abandoned for new technologies. The rail industry began to drive the local economy, moving the focus of the city inland and away from the riverfront.

${ }^{14}$ Petitcodiac Riverkeeper. Historical Values Accessed March 15, 2017. http://petitcodiac. org/our-river-historical-values 
"When understood, the landscape may be comprehended as one of the most accurate indicators of a society, its values, its technology, and its aspirations." ${ }^{15}$

With an economic focus, the culture of this time valued prosperity, growth and action and this was to be seen in the relationship with the landscape. The presence - or spirit - of the landscape was arguably replaced by financial gains, reflected in the abandonment of the river as it became economically obsolete and merely an obstacle to cross.

\section{Moving the River}

Moncton is part of the Greater Moncton Area which consists of the city proper, the adjacent town of Dieppe and the town of Riverview that lies across the river. Although one bridge existed to cross from Moncton to Riverview and the outlying areas, the expansion of the area coupled with the increase in automobiles called for an additional route by the mid-1960's.

Evidently, a new crossing was to be constructed. However, the shift in the relationship between the city and the natural environment only escalated.

"A Great Promise of Unlimited Progress - the promise of domination of nature, of material abundance, of the greatest happiness for the greatest number, and of unimpeded personal freedom - has sustained the hopes and faith of the generation since the beginning of the indistrial age."16

With little economic use for the river and a general lack of

\footnotetext{
${ }^{15}$ M.D. Murphy, Landscape Architecture Theory: An Evolving Body of Thought, (Waveland, 2005), 11.

${ }^{16}$ E. Fromm, To have Or to be?, Volume 50 (1st edn, New York, Harper \& Row, 1976), 1.
} 
appreciation for the landscape, the city planned for a causeway to be built for crossing, damming the water. The development plans persisted despite warnings that not all of the future impacts could be predicted, however, restricted water flow would surely cause tidal silt deposits to build up and fill in much of the river's area.

Floodgates were introduced and expected to assist with impeded fish passage for migration. The structure was built to the south beyond the natural course of the river, creating a pinch point for the river to reroute through - when allowed. The five tenmeter-wide gates were to be opened at peak migration times or for spring thaw and be closed for the remainder of each year, resulting in the formation of a headpond to the west of the causeway.

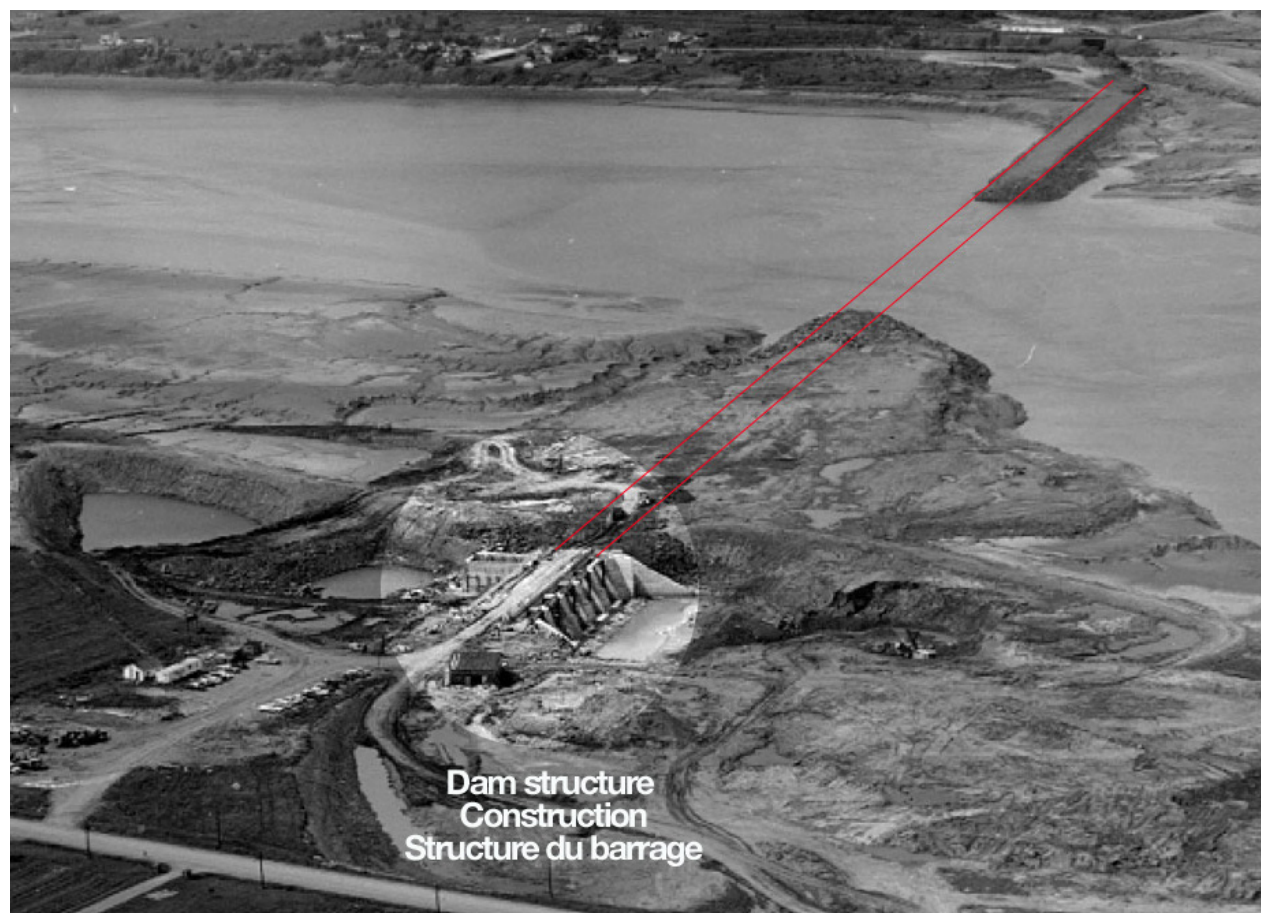

Figure 14: Construction of causeway 1966 


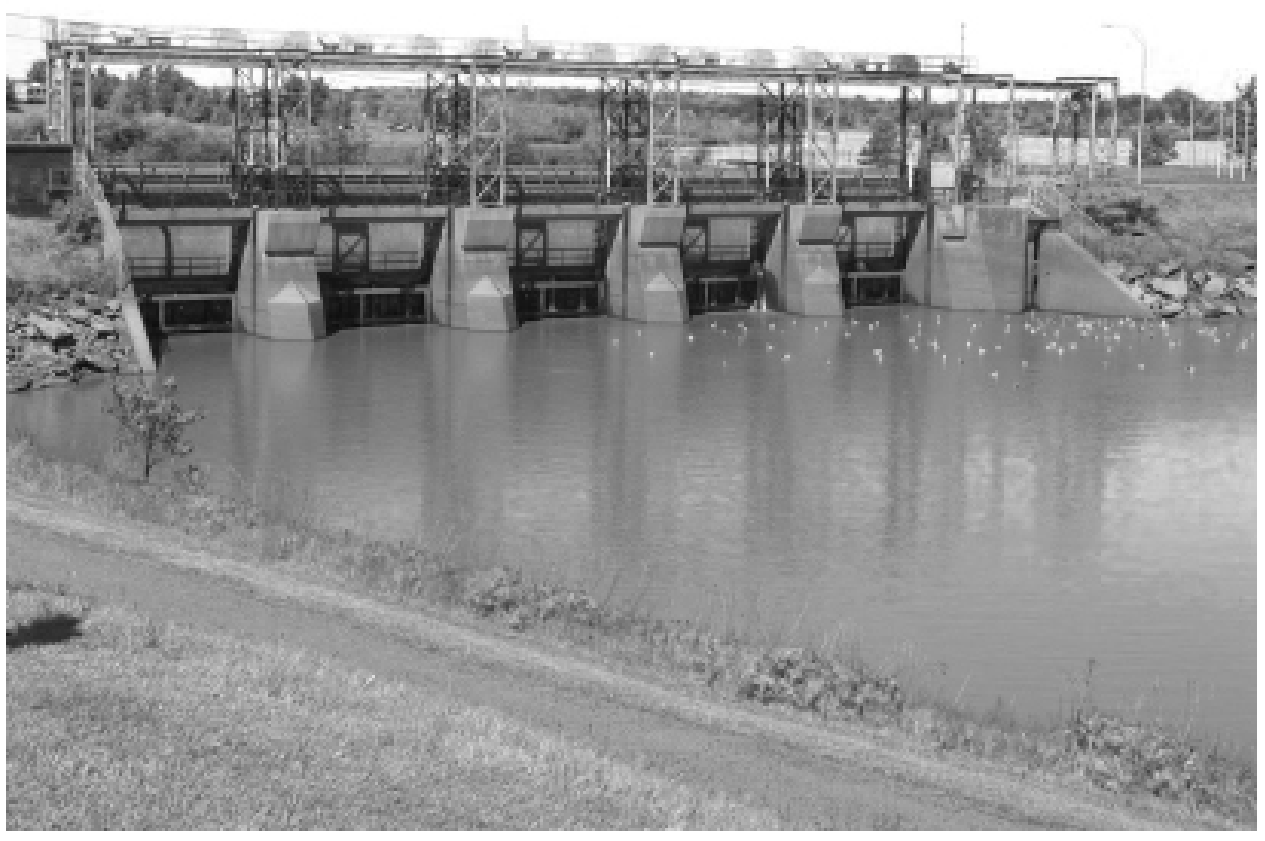

Figure 15: East side of floodgates (current condition) 


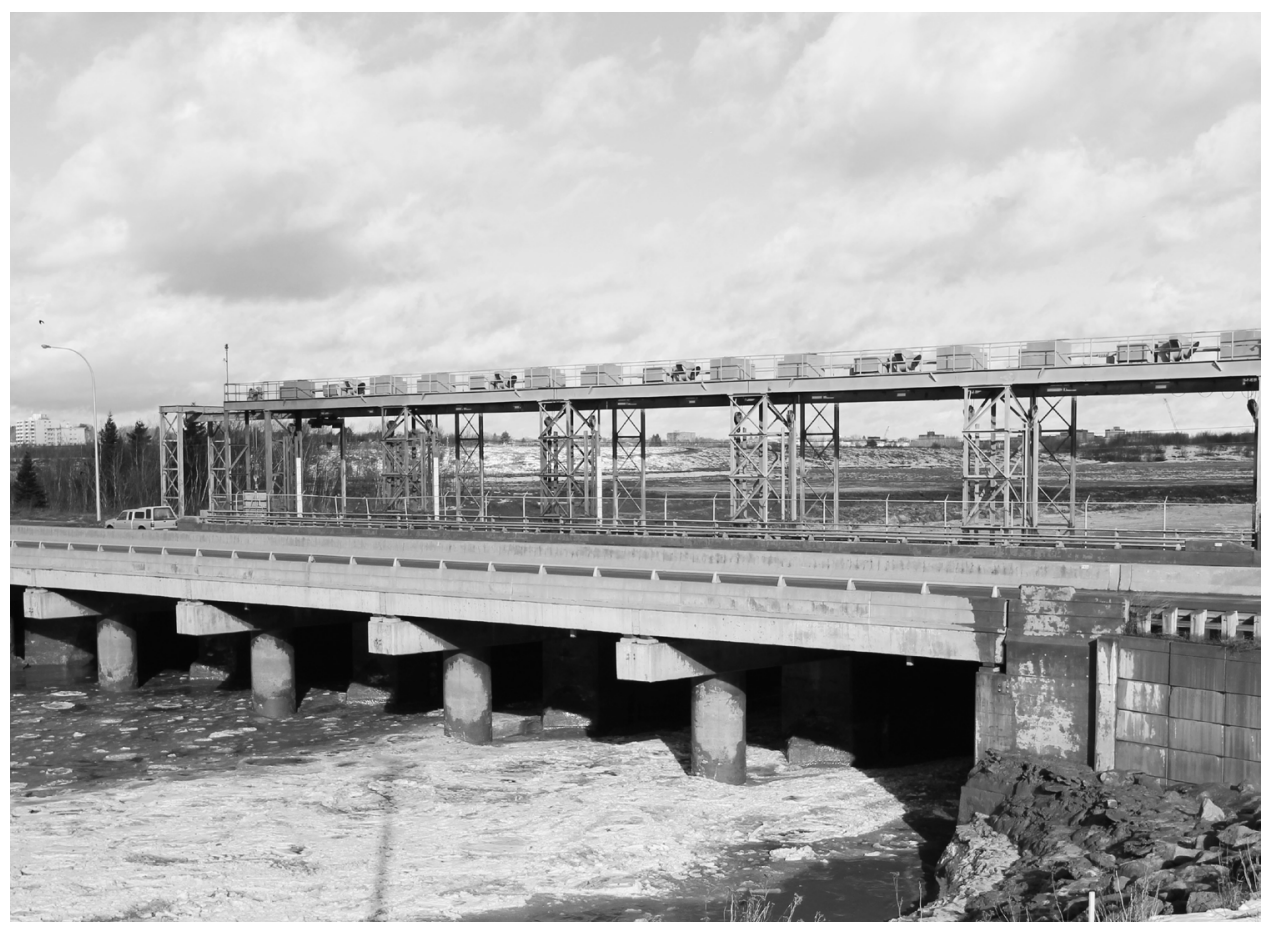

Figure 16: West side of floodgates (current condition) 


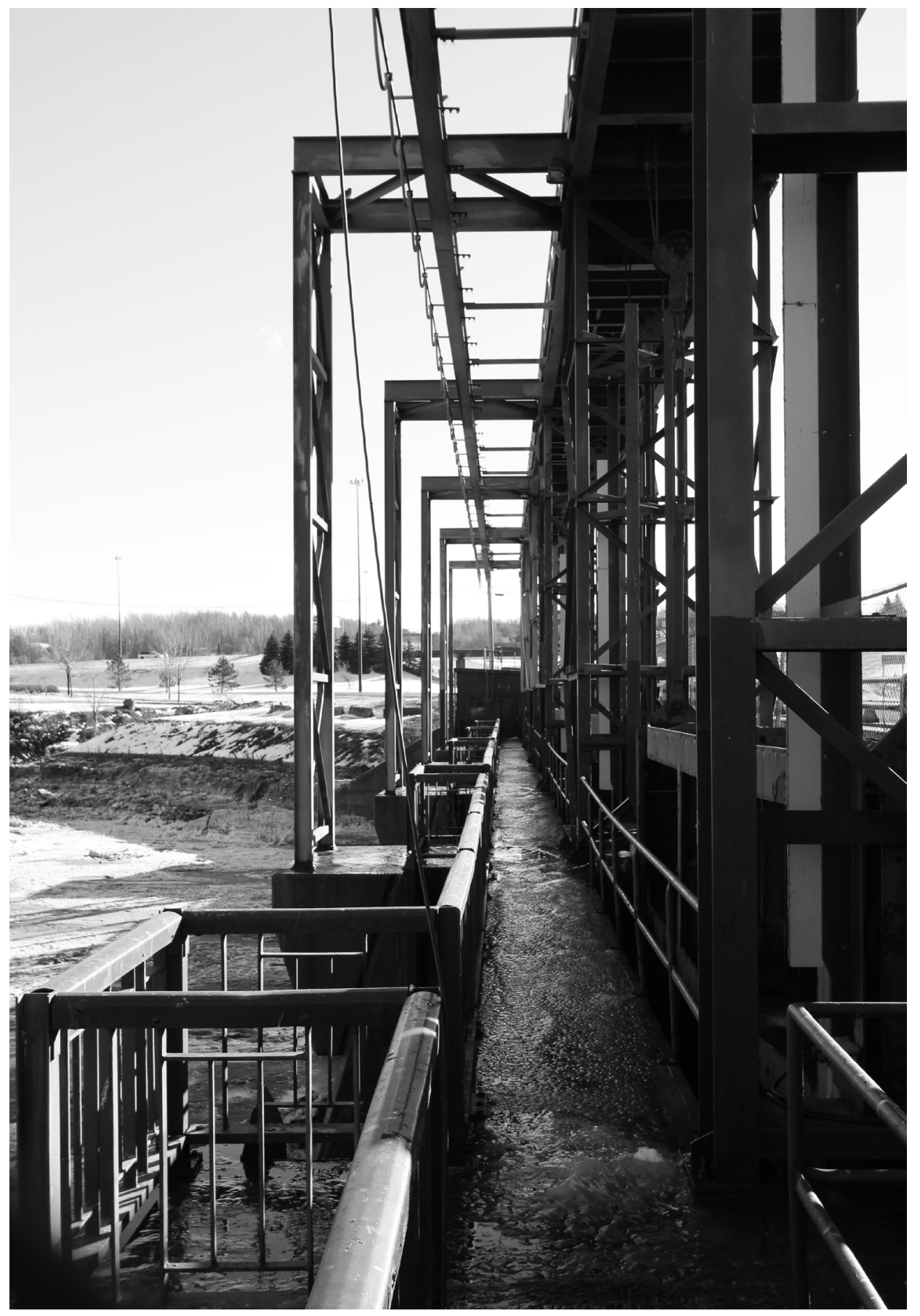

Figure 17: Floodgates (current condition) 


\section{Changing the Land Conditions}

As expected, silt deposited against the causeway and along the projection of the river. The narrowed river not only created a drastic change in the landscape, but much of the previously thriving ecosystem was also impacted.

Only certain species were able to migrate through the openings of the floodgates, resulting in the obstruction of fish passage for two-thirds of the river system. The most prominent species for the fishing industry - salmon - was greatly affected by the changes and the inevitable collapse of the industry soon followed. Other native species of the Petiticodiac River dramatically declined and some even saw regional extinction. ${ }^{17}$

The city was able to freely cross the river in two places, but water travel, which once accommodated Tall Ships, was no longer possible. The shallow, narrow body of water became enclosed by deep mudflats that engulfed the old wharves as if they were never there.

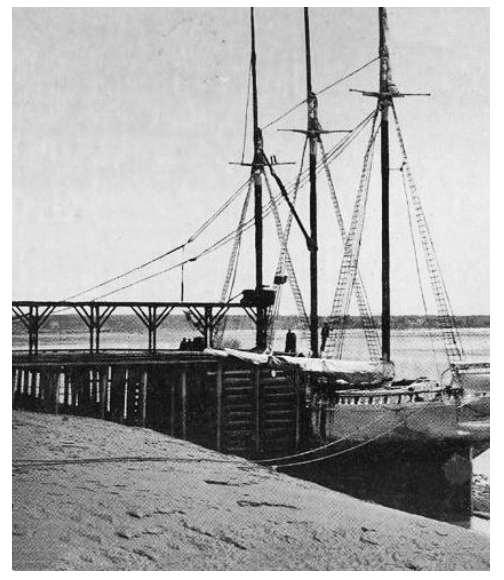

Figure 18. Wharf in 1800's;

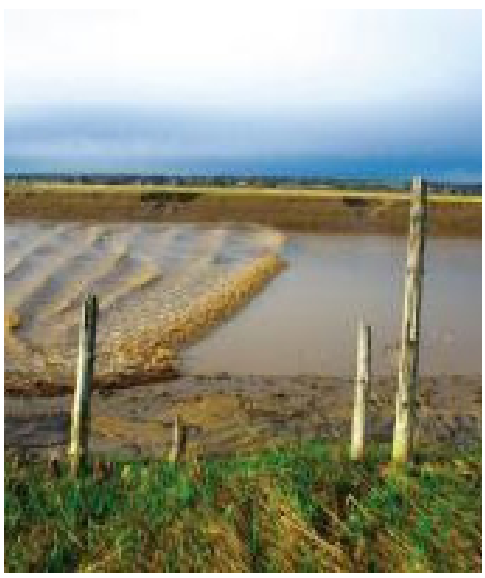

Figure 19. Current remnants of wharf

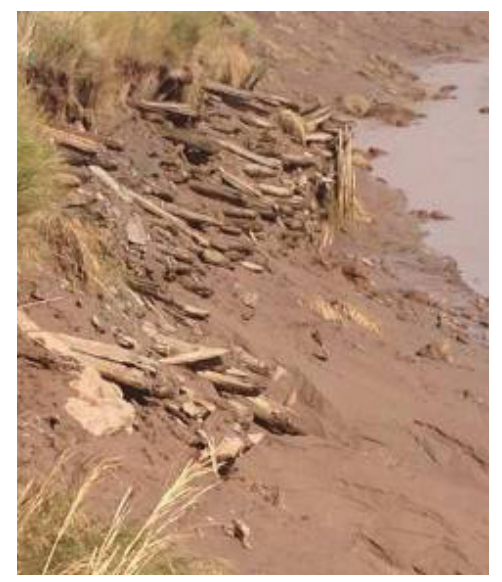

Figure 20. Recently uncovered remnants of wharf resulting from the river widening

${ }^{17}$ Petitcodiac Riverkeeper. Petitcodiac Causeway: Imapacts on the Ecosystem. Accessed December 16, 2016. http://petitcodiac.org/petitcodiac-causeway/impacts-on-theecosystem/ 
The river that once served to anchor the city and sustain the community became not only abandoned, but also littered. A city landfill opened on the newly filled area along the riverbank in 1968, shortly after the completion of the causeway. Everyday and chemical waste was deposited until its closure in 1992. The toxins would later seep into the surrounding waterways and further impact the ecosystem and natural resources. ${ }^{18}$ The attitude towards the natural landscape became very clear - it was controlled by the people, for the people.

\footnotetext{
"Most people [...] do not regard humans as a component of an ecological organization. We reserve a special status for humans and define ourselves in rather different terms. The ecosystem is considered to be an environment we control, not one we are a part of." ${ }^{19}$
}

Despite the presumed control of the land, the geological conditions adapted in unpredicted ways as a surprising 10 million cubic meters of silt deposited by the causeway in the first three years, and continued to settle downstream thereafter. ${ }^{18}$ Subsequently, the unique tidal bore that once attracted visitors all but disappeared to the eye, decreasing from a couple of meters in height to a ripple, and the community became the first in Canada to lose its inherent right to a navigable waterway. ${ }^{18}$ Furthermore, unforeseen leachate leakage from the landfill created a hostile environment for plant and animal life and continues to threaten the ecology today. ${ }^{20}$

Although some may argue that these impacts can be fixed with

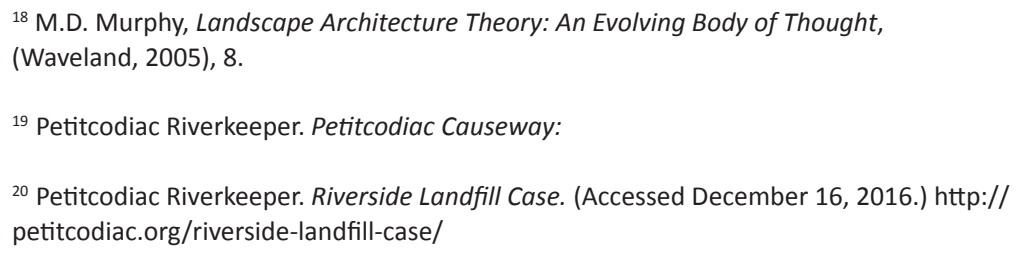


time, I would counter that restoring a collapsed ecosystem to what it was is virtually impossible, and leachate leakage from the landfill has proven to be unmanageable thus far. The conditions have therefore developed beyond our management and/or comprehension, regardless of the illusion of control. This humbling reality forces us to reconsider the interplay between humans and landscape and leads us to understand the relationship as just that: a relationship, rather than an ownership.

\section{Bring the River Back a bit to the Right.}

Contemporary values have begun to demonstrate a renewed appreciation for the environment and land as our awareness increases regarding the complexities of these systems. Global warming, nutritional awareness and a greater understanding of the psychological influences we experience from our environment have all impacted our perception of the relationships we have with natural systems.

As has been the case previously, our values and aspirations are being reflected in the landscape. A current emphasis on living in harmony with the environment and integrating natural elements into our urban fabric has shifted our approach to landscape design. Recently, there has been a particular interest in the potential of urban waterfront areas, desired for their beauty, therapeutic effect and artistic or spiritual value. The movement, sound, and often smell of bodies of water engages our senses to create stimulating environments and provide promising areas for rich and unique experiences. Therefore, many cities with waterfront property are centralizing greening in these areas. We continually see waterfront redevelopments where industrial zones 
have fallen and the abandoned space requires attention.

In an attempt to bring back the presence of the river within the city of Moncton and remedy some of the negative conditions that have resulted from its past, major plans to re-adapt the landscape have been put forth. The aim is to create a healthier river and ecosystem - albeit not the original one - by partially removing the causeway and replacing the removed section with a bridge. ${ }^{21}$

Although construction plans are currently underway, the initial phase of the project began in 2010 when the floodgates were permanently opened to allow the water to funnel through the channels year-round, initiating the expansion of the river banks to the east of the causeway and emptying the lake to the west.

However, removing the entire causeway would result in the river reclaiming the land where the landfill is situated. Approximately a third of the dam will therefore remain on the north end, extending past the landfill in an attempt to prevent the water from disrupting the area. ${ }^{22}$ Current proposals suggest that on the south end, the river will be guided back to its initial course, passing north of the floodgates and leaving that area to be once again dry land.

Since the opening of the gates in 2010 there has been a noticeable increase in the river depth and width, as well as the reappearance of the tidal bore. The wave has risen to just under one meter in height and has brought internationally acclaimed surfers to experience it first hand. Ecological studies have also found

${ }^{21}$ CBC News. Petitcodiac River Bridge Construction begins in Spring. (Accessed March 30, 2017). http://www.cbc.ca/news/canada/new-brunswick/petitcodiac-river-bridgeannoucement-daniel-leblanc-1.3899651

22 Ibid. 
increases in fish populations, causing excitement in the local biological community.

With the ability to freely flow in the future, the width and depth of the river - along with the tidal bore height - will continue to increase with the hopes of inviting traffic and recreation back to the water.

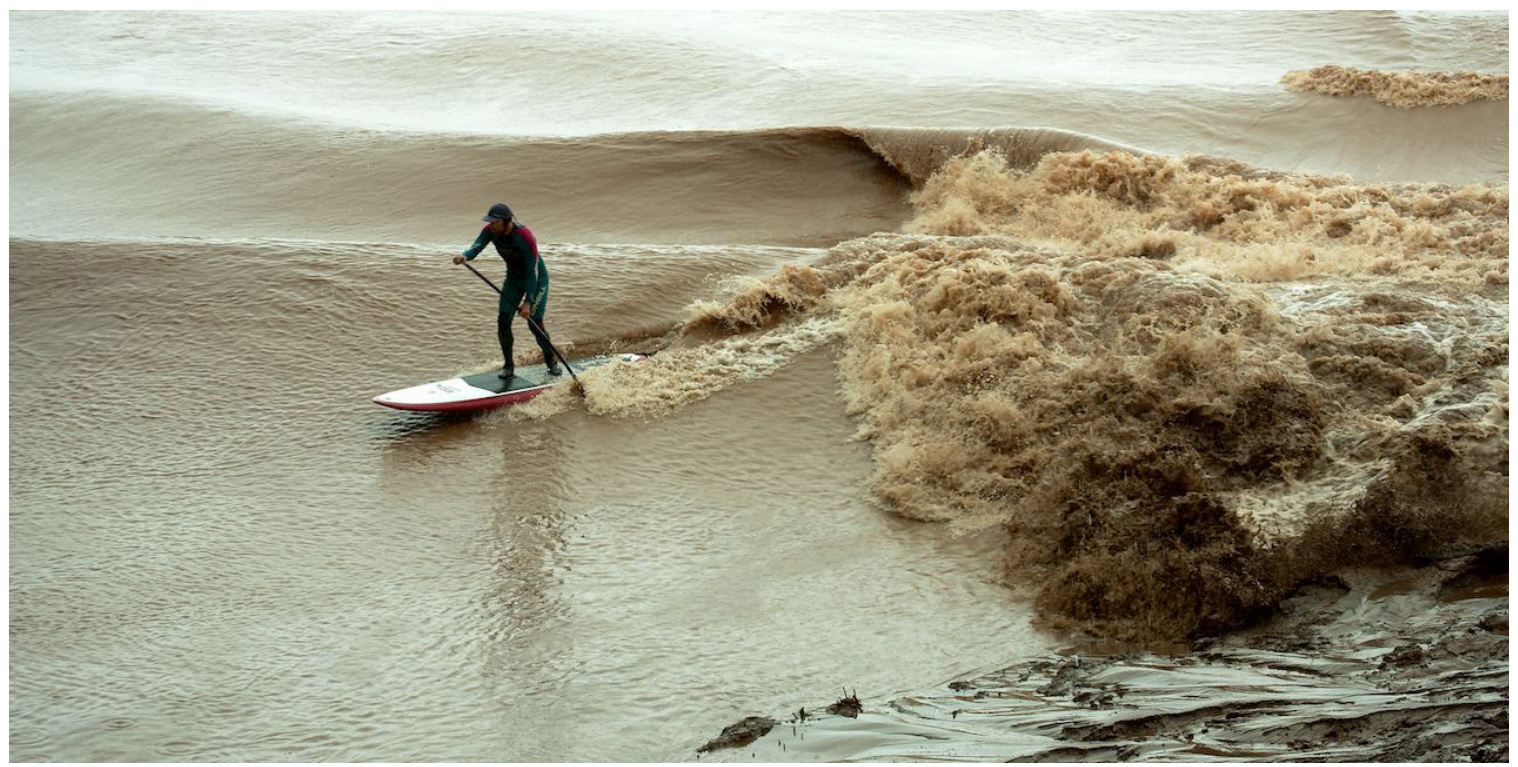

Figure 21: Surfing the tidal bore 
The Performance

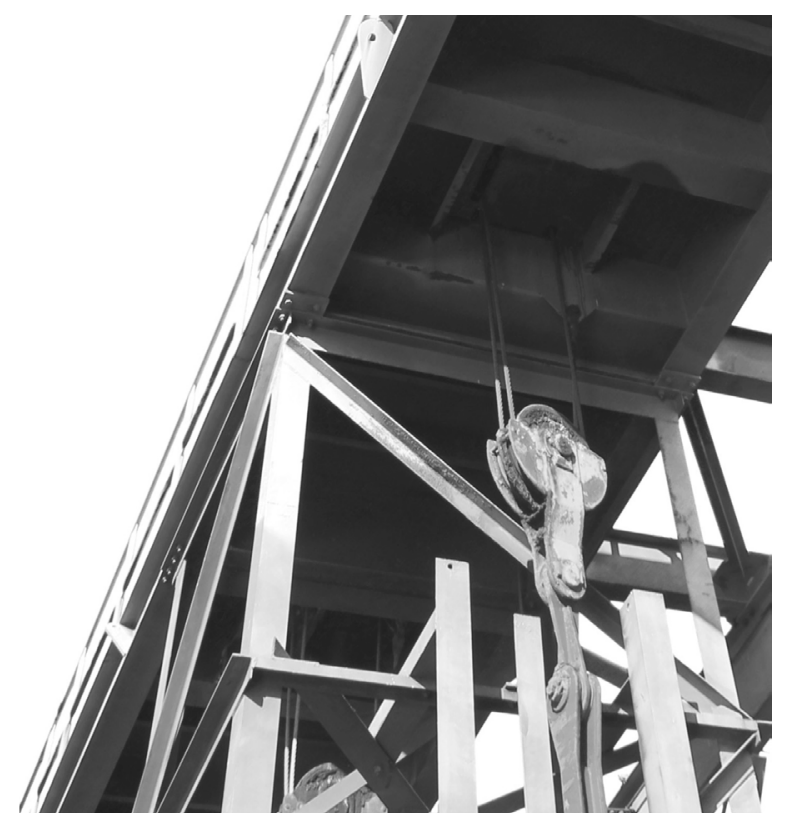

Figure 22: Photo of floodgates; pulley system detail 


\section{Strategy}

The architecture responds to the changing land conditions of the future while maintaining the presence of the past in an effort to enrich the cultural landscape. Providing the opportunity to explore existing infrastructure allows the community to experience memories of the site, while engaging in current cultural activities.

Architectural elements guide the user through the place, prompting mindfulness of the details within the site. The intention is to strengthen the relationship with the landscape and draw awareness to the conditions that inform place. The anticipated changes to the land call for some fixed responses, while other elements are intended to fluctuate with the environmental elements. 


\section{Site}

In addition to the historical and industrial aspects of the site previously outlined, there is also a unique circulation condition in which multiple transportation paths intersect and overlap. The active railway passes over the beginning of the river crossing on the north side, which will span above the water traffic below. Pedestrian paths also run along the river on either side and connect the downtown areas of Moncton and Riverview to the river crossing - passing the prominent Farmer's Markets along the way. A great potential therefore exists for the site to be an activity hub within the city, but is currently stunted by the causeway.

Proper pedestrian and bike lanes do not exist on the narrow causeway, rendering it unsafe to cross by foot. Along with being an obvious barrier to water traffic, the causeway also interrupts the waterfront paths which could continue under the new river crossing and, on the south side, connect to the outdoor recreational fields nearby.

With the surrounding marshland, waterfront trails, and connection to the river, the site invites activities such as birdwatching, fishing and biking, or a peaceful stroll through the beautiful landscape. 


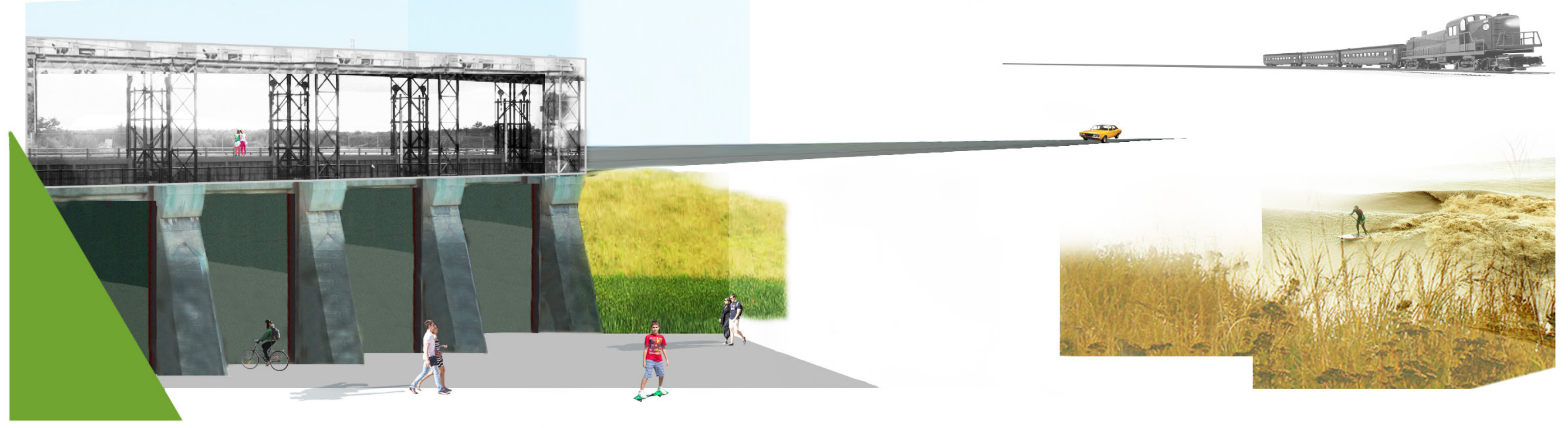




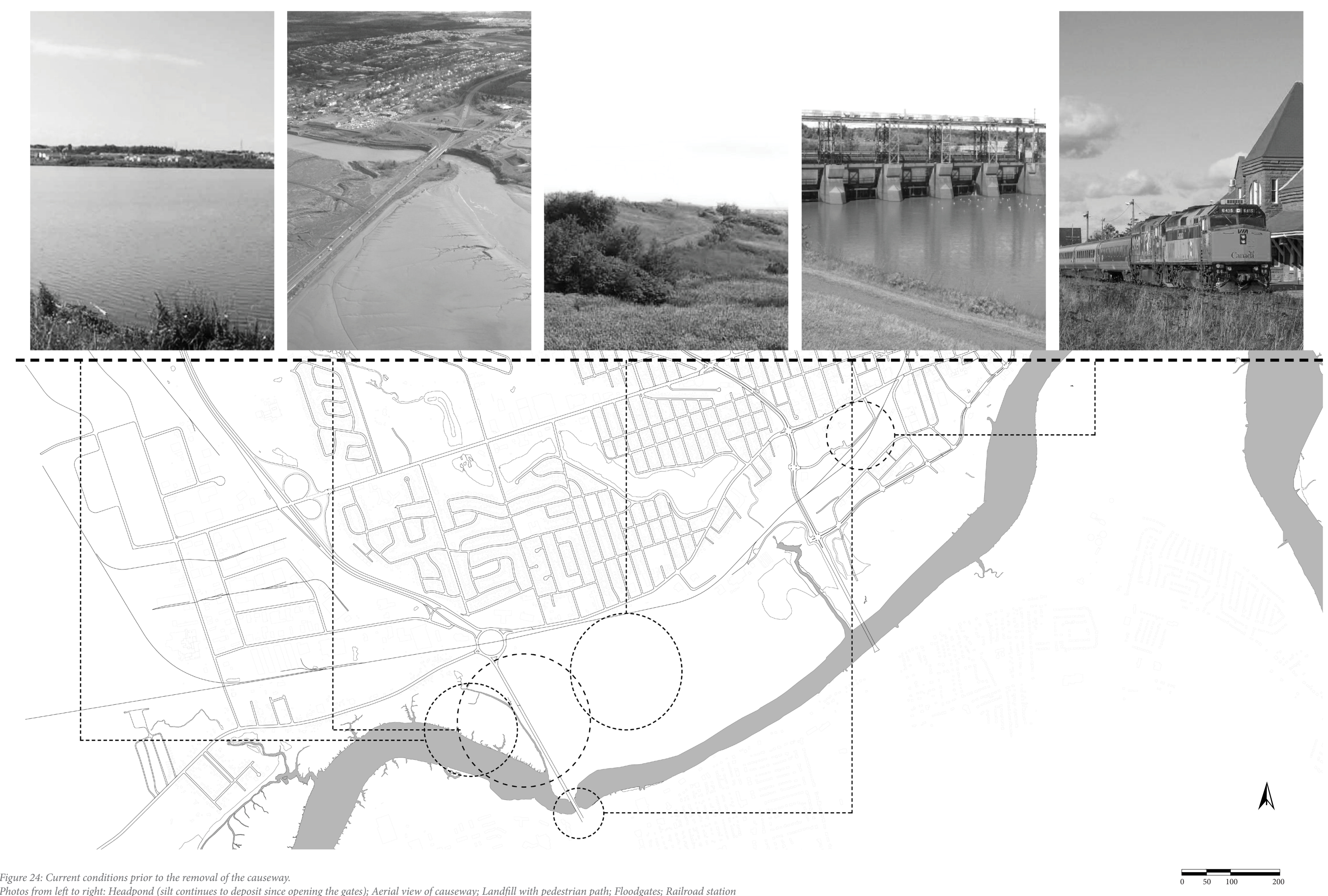




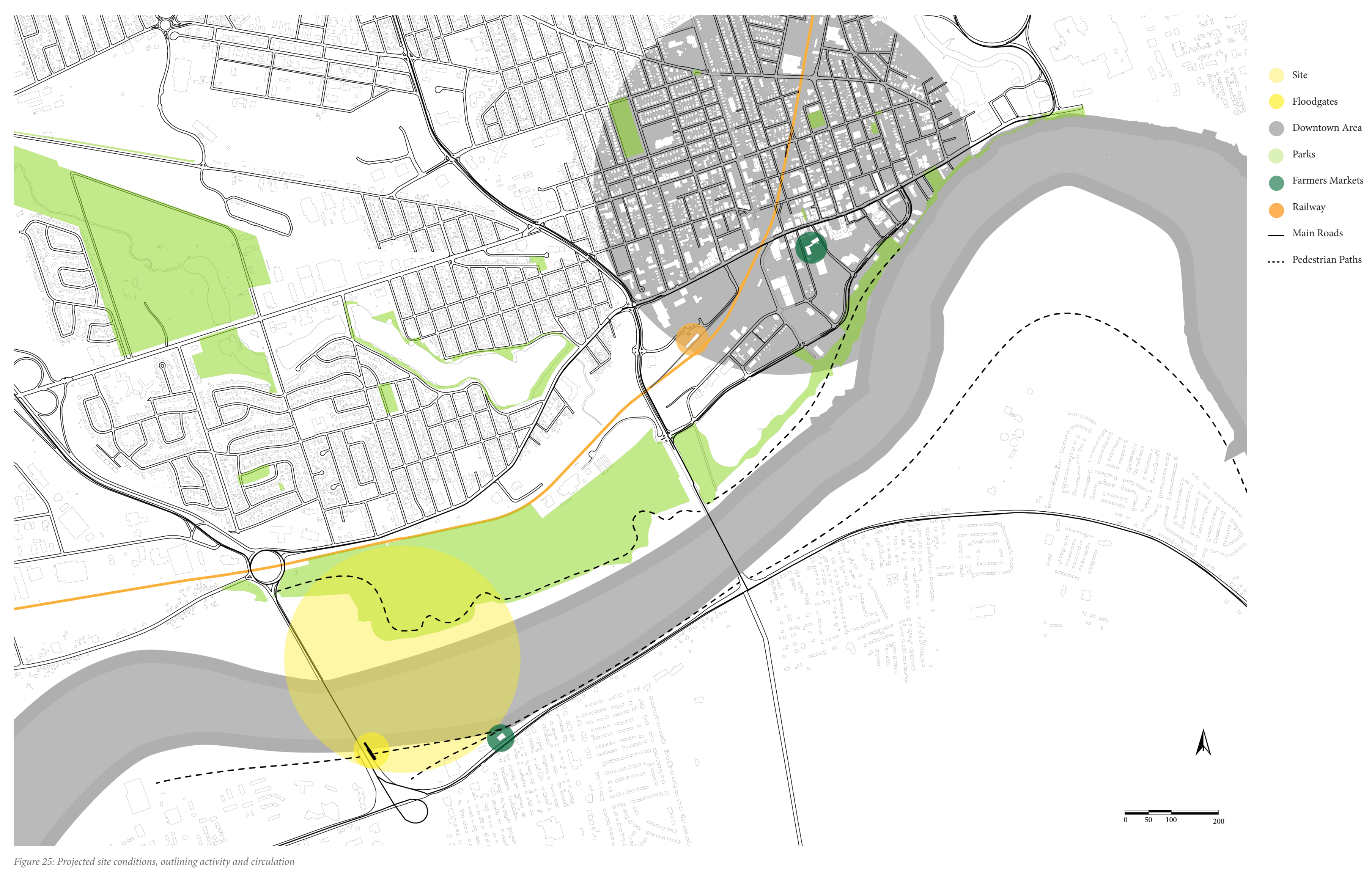




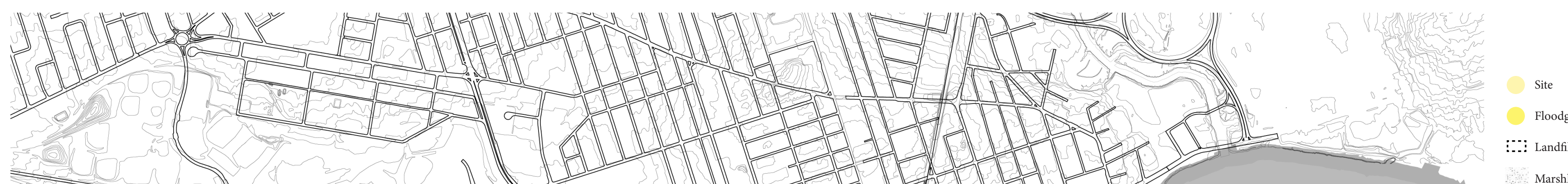

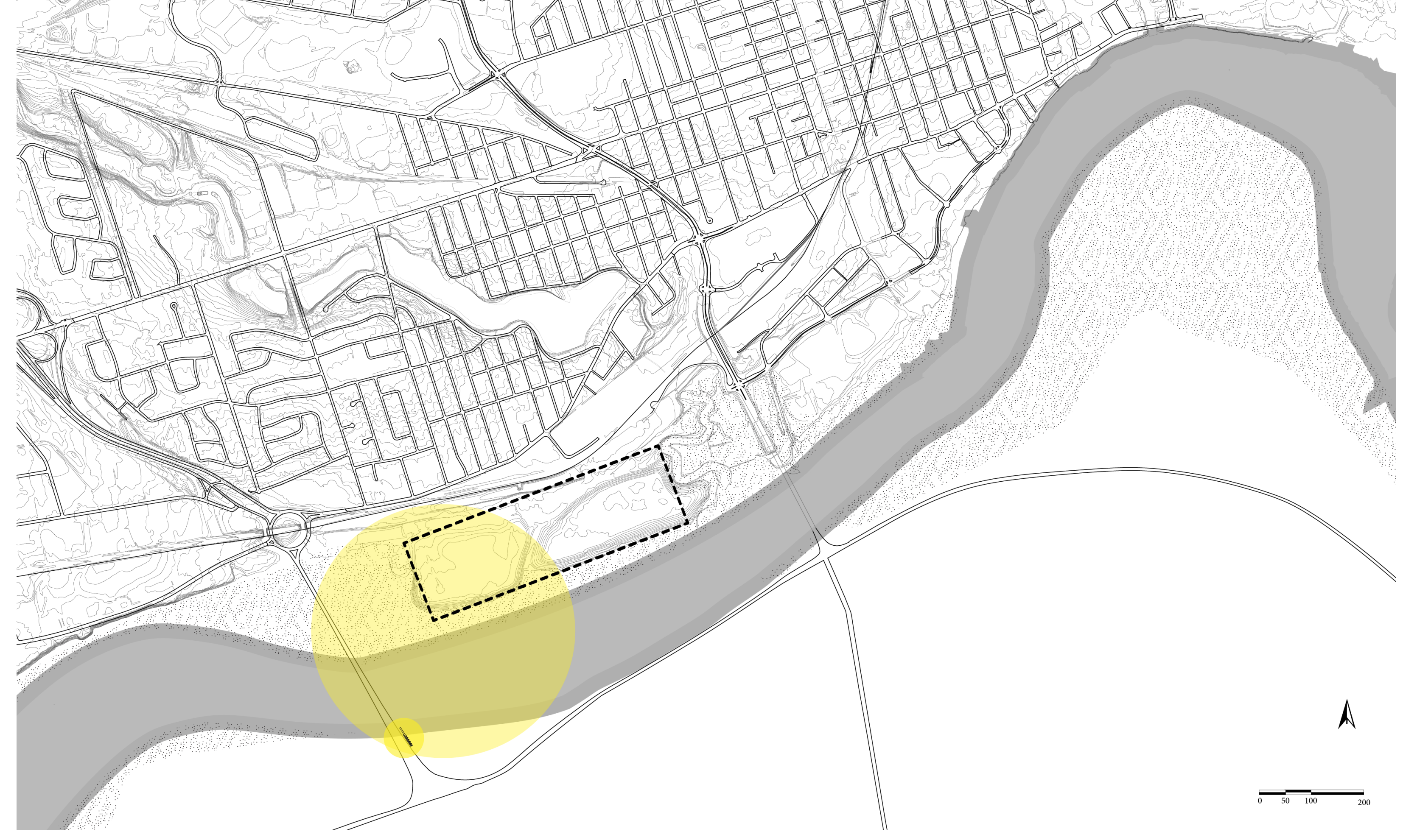




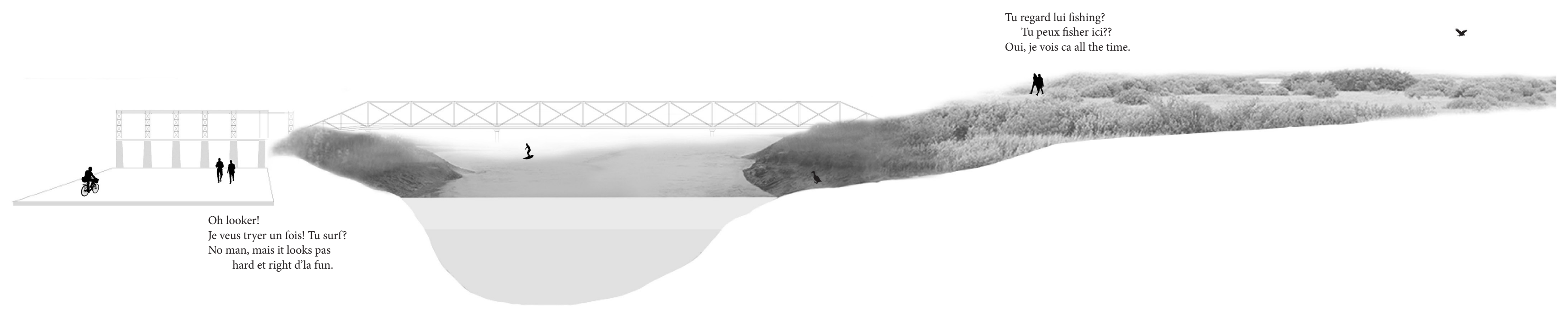

Figure 27: Projected site section, demonstrating local Chic language

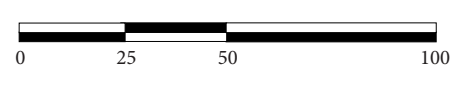




\section{The Landfill}

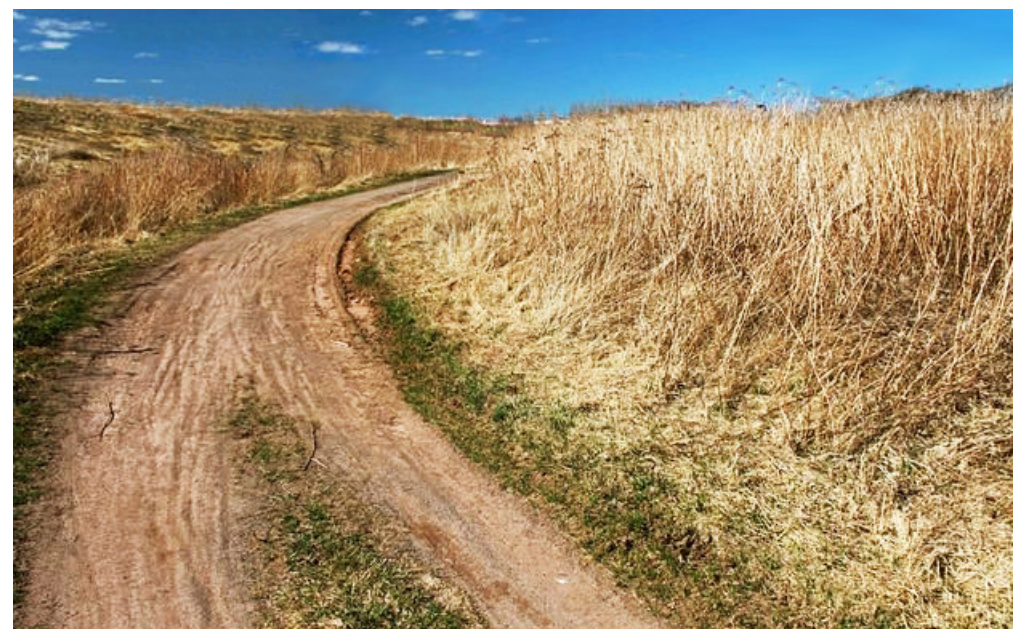

Figure 28: Image of the Riverside Trail on the landfill

What is called the Riverside Trail winds through the greenery that covers the landfill, connecting downtown Moncton to the river crossing. The green space is raised above the height of the marsh and mudflats, and lush in a vegetative cover. However, below the surface and out of sight from the city above, the earth is active - trying to process and decompose the densely-packed waste of the city's past. The only hint we have of the slow process is from the large pipes emerging from the ground. Common to landfills, they act by collecting gas emissions that result from the biological and chemical processes as the waste breaks down, providing a potential energy source.

Although the trail that crosses the park offers a direct route from the river crossing to downtown Moncton, a common complaint about the area is that it is uninviting, being cut off from the city by the rail line and consequently unlit at night. Using the gas production as energy, lighting features that extrude from the pipes are designed to act as an inviting sculptural element for the explorer walking the trails during the day, while also providing a 
light source for the commuter in the evening.

The lights draw attention to the pipes in an effort to connect the green space to the underground waste site, forming a narrative between the habitable and the hidden. By expressing the activity of the landfill through the lighting features, the natural remediation process becomes a display and the history of the site maintains a presence, rather than being concealed.

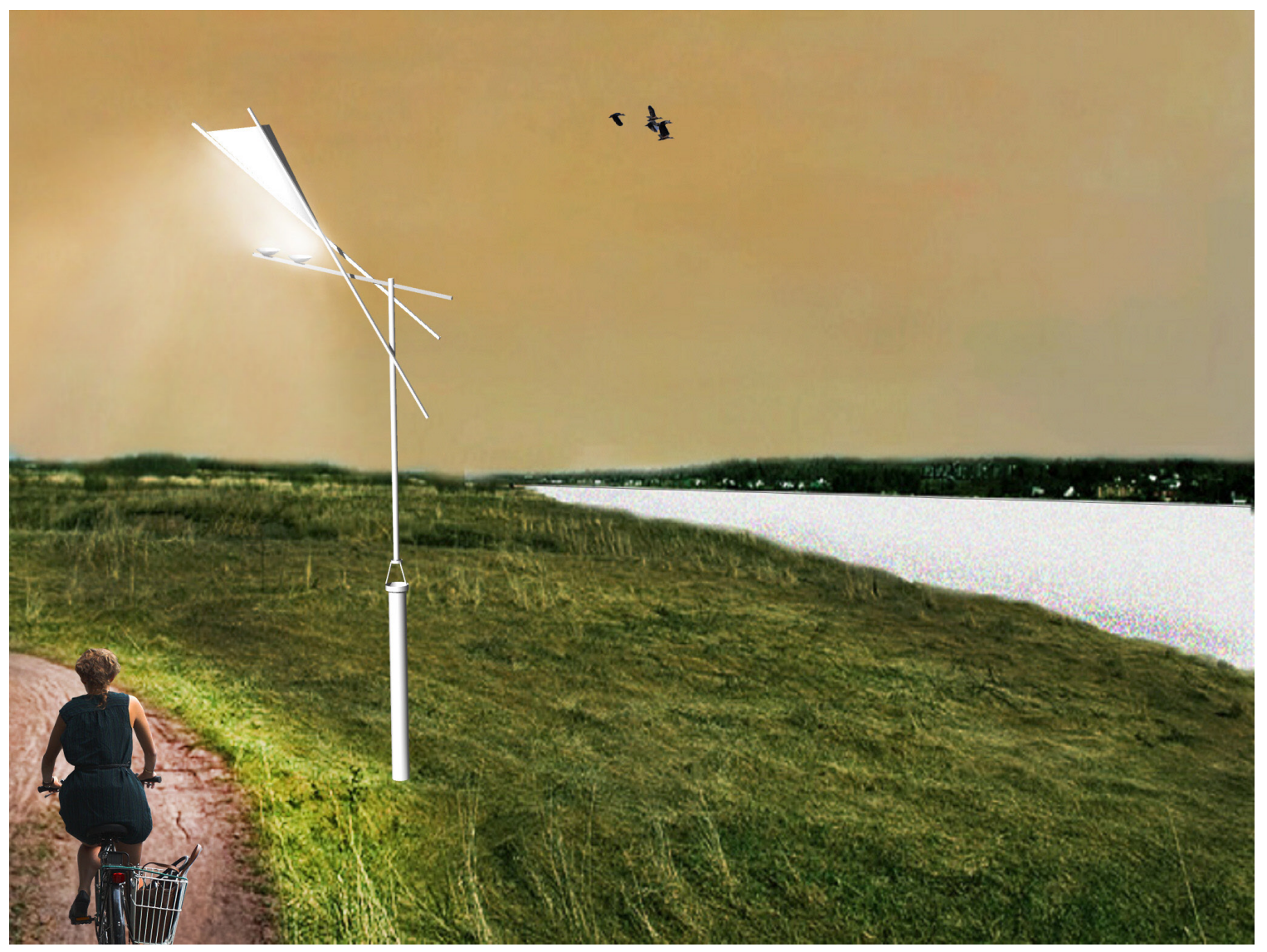

Figure 29: Proposed design elements on the landfill 
The landfill is situated on marshland and occupies the space where the river once flowed. Unsurprisingly, leachate has trickled through the soft earth to contaminate the river, although it is unknown how far into the earth and waterways contamination has spread. Despite efforts put forth by the city to manage the problem in 2010, the issue persists. ${ }^{23}$ The removal of the causeway and subsequent expansion of the river will pose a renewed and even greater threat to the health of the water and ecosystem as the free-flowing river reclaims the land to meet the landfill.

Unfortunately, due to a lack of area - with the trajectory of the river running directly through the landfill - and considering the immediate plans to begin the process of removing the causeway, biological remediation is an unlikely option.

In response to this, the thesis proposes the design of a retaining barrier to be incorporated into the site, acting as a barrier between the water and the contaminated earth. Because the landfill is raised above the height of the surrounding marsh area, the barrier will extend well above the river elevation to prevent run-off into the water and to anticipate rising water levels.

The barrier will therefore prevent a visual connection from the trail to the river. As the explorer strolls along the path and looks to the south, they are unable to see the river itself, but can see across to the town of Riverview and hear the noise of the water running in between. A symbolic significance is also suggested, reinforcing the detachment of the landfill from the landscape and the inability of the two to co-exist harmoniously. It acts as a reminder of the implications of the past interventions on the land.

${ }^{23}$ Petitcodiac Riverkeeper. Riverside Landfill Case. 


\section{The River}

There is an ephemeral quality to the landscape, disappearing and reappearing with the tide to create vastly different scenes. A visitor may only ever see one condition and leave thinking the extensive mudflats always separate the shore and the river. However, the local commuter notices the condition on their way to work and is aware of the change on their way home, reminding them of the passing of time. On the rare occasion their schedule aligns with the incoming tide. They may hear the odd, yet familiar sound of the tidal bore rushing through, giving those who happen to be near an exclusive show. Visitors who know of the spectacle wait on the riverfront with cameras ready, not wanting to miss the performance.

Similarly, the Hopewell Rocks Beach down-river only appears to exist for approximately six hours at a time before inaccessibly hiding under the water. Those who missed the opportunity to explore the shore must wait for the next occasion, scheduled at different times each day.

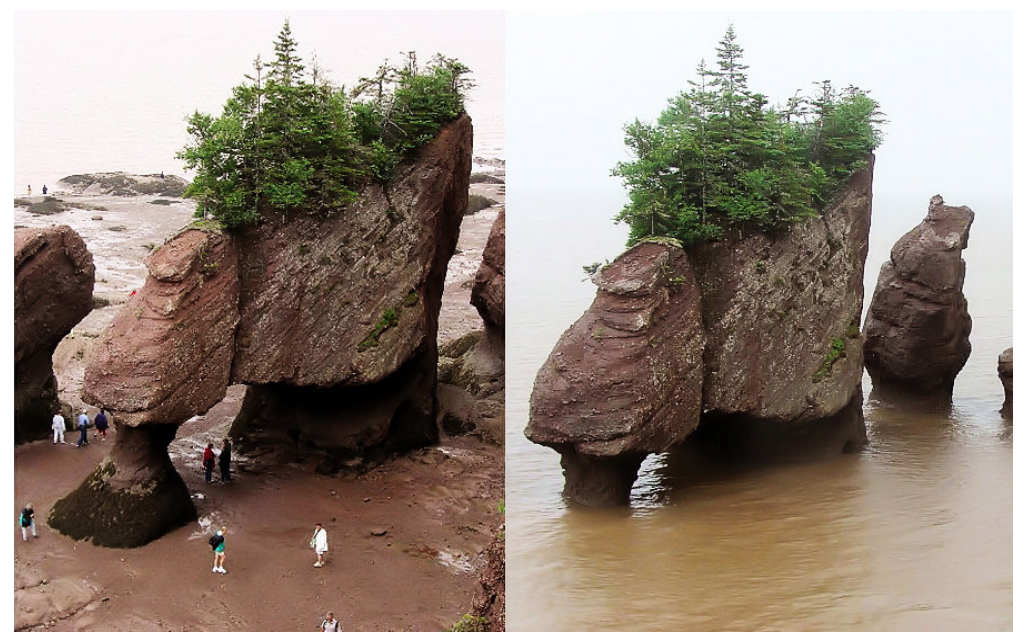

Figure 30: Hopewell Rocks at high and low tide 
Inspired by these conditions, the design explores the ephemerality of the site, exposing new areas to discover as the water recedes and having it reclaimed by the tide as it floods. The experience and activities therefore changes as the landscape changes and allows the user to view and interact with the site from different perspectives, depending on the condition at the time. The result is a heightened connection to, and understanding of, the landscape as the experience becomes inherently dependent on it.

The retaining barrier designed to separate the river from the landfill invites a habitable opportunity due to its required mass. As the wall narrows near the upper portion, a ledge is carved along the edge of the water to create a waterfront path. Frequent access nodes invite the explorer to cross from the riverside trail through the retaining wall and navigate down to the river path when accessible. As the tide climbs up toward the path, they cross back through the wall to the trail, maintaining a connection to the river only through sound. 


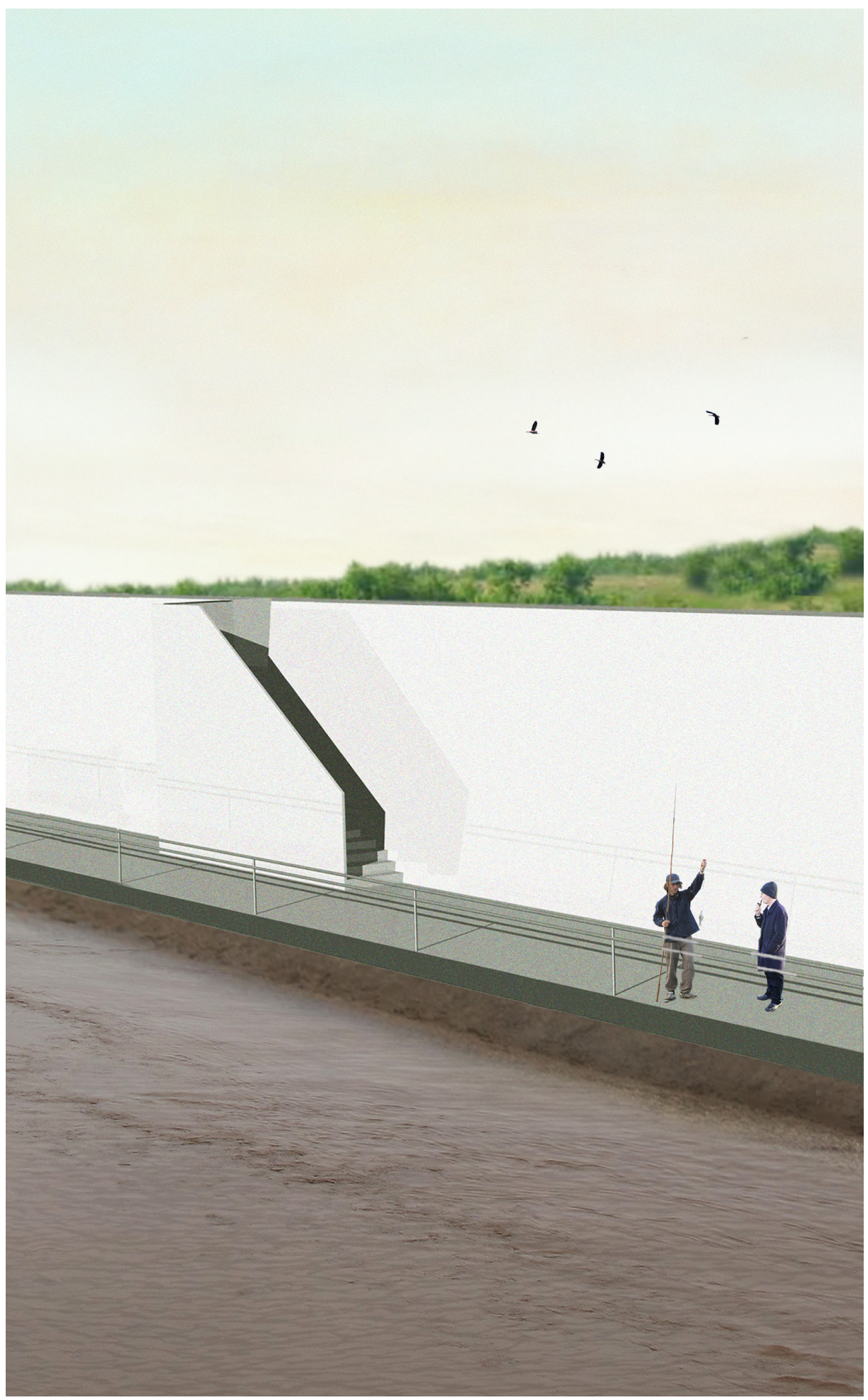

Figure 31: Proposed riverside walkway at low tide 
Across the river, the industrial floodgates tower above the landscape, contrasting the flat marsh area and acting as a landmark. They serve as a welcoming gate and an introduction to the city, being a point of arrival along main routes into and out of the city.

Although the gates are situated outside the river's new trajectory, they were once the controlling device of the river - allowing or denying it passage. Having a direct effect on the landscape, they act as a structural artifact in the cultural landscape and express the evolution of the site. The concrete forms that separate the five gates are marked with water lines and sediment that have created permanent drawings on the surface, while the pulley system in the steel assembly above gives clues to the structure's past use.

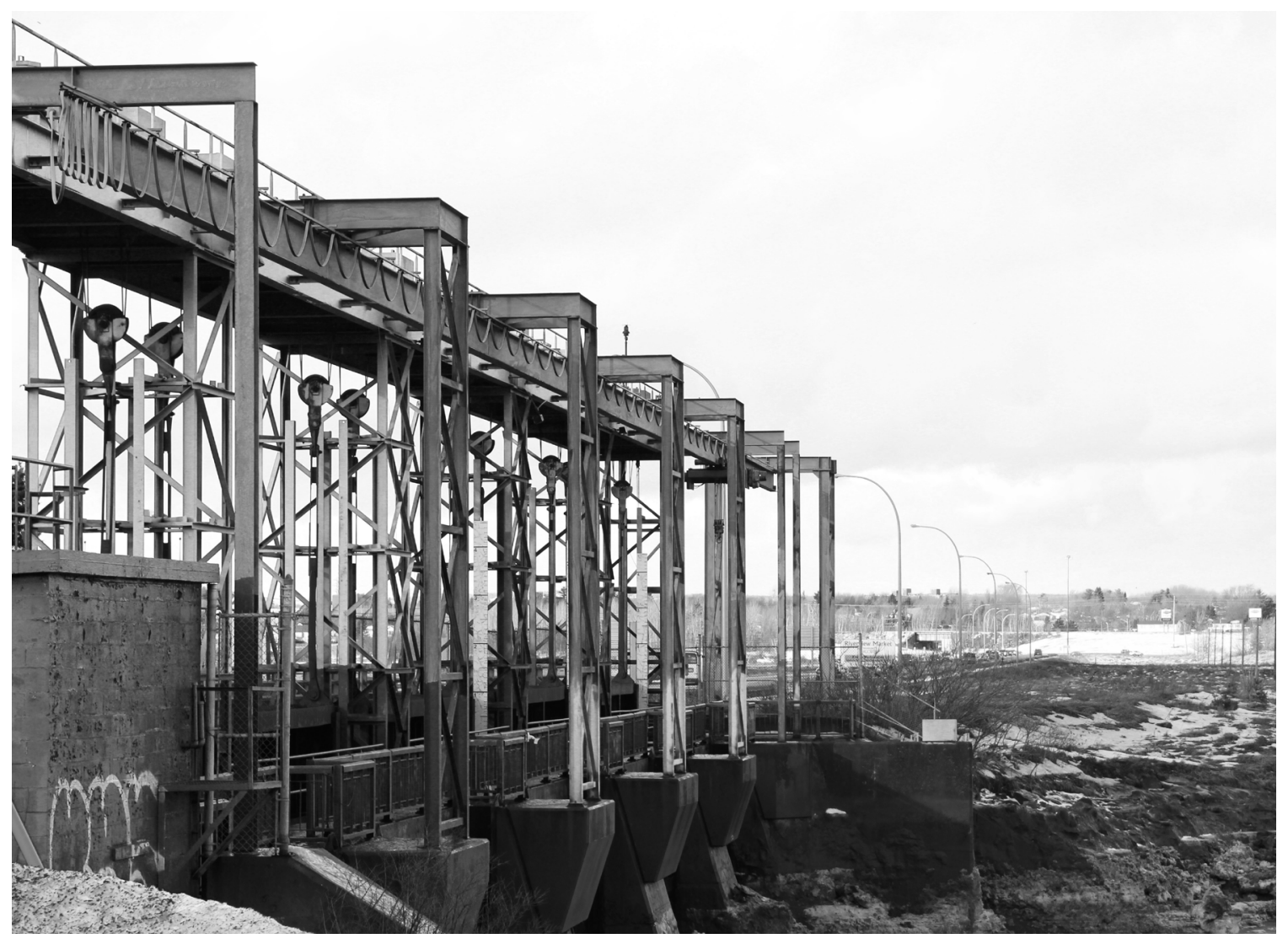

Figure 32: Floodgates (current condition) 
The waterfront path that runs along the south riverbank currently ends at the causeway, leading up to meet the grade of the town. With the shifted river location, the design invites the path to continue under the river crossing, having the channels where the water once flowed act as pedestrian thoroughfares.

As the explorer passes through the concrete structure and notices the traces left on the walls, the written memories of the river and the monumentality of the structure reminds them of the force of the water and the scale of the intervention required to redirect it. The user is therefore invited on a journey through the space, as well as time.

Because the elevation of the floodgates are below grade, the earth between them and the river forms a retaining condition, blocking the view of the river as the path descends. To maintain a connection between the old and new river channels, the gates that functioned to retain the water are designed to move vertically in conjunction with the tide. The display functions as a tidal clock, drawing attention to the often subconscious awareness of the impressive tidal changes. The spatial and acoustic qualities of the thoroughfares are in constant fluctuation as a result. 


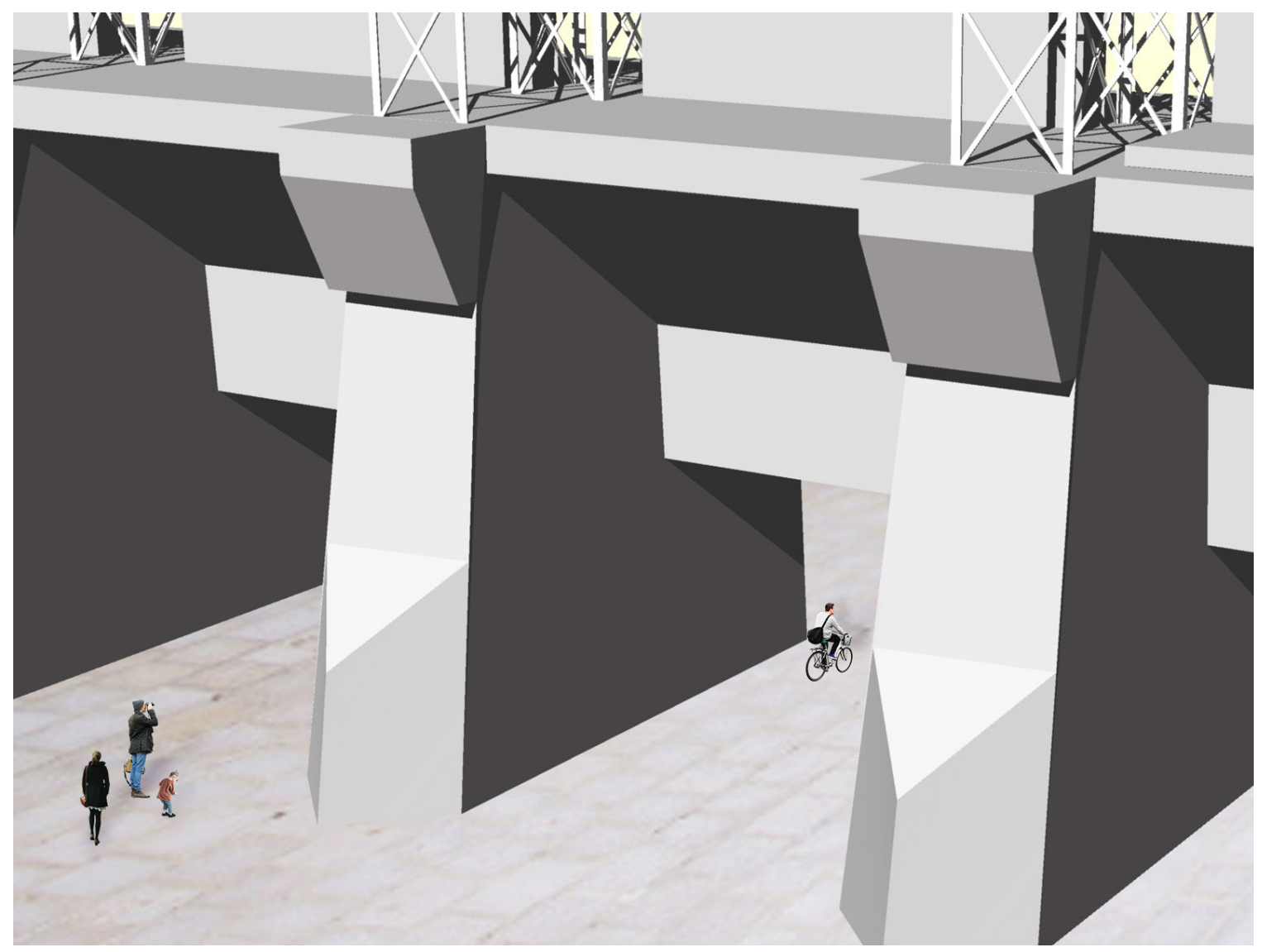

Figure 33: Showing floodgates as pedestrian thoroughfare at mid-tide 


\section{The People}

Above the thoroughfares, the river crossing arrives at the north end of the steel structure which acts to control and support the gates. The industrial appearance of the structure gives it a prominent presence on the site as it stands out against the natural landscape and modest construction. In contrast to the massive concrete forms below, which convey permanence through their materiality and weathered appearance, the steel section resembles stage scaffolding, appearing temporary. The pulley system housed within it that maneuvers the gates also suggests change and movement.

Standing tall among the flat marshland and centralized in the activity of the site, the structure naturally captures attention from below. Its flexibility, nature and location therefore invites the opportunity for it to figuratively and physically become a stage for cultural events.

By lightly attaching stage platforms to the top of the gates, flexible performance areas are created that move with the gates as they move with the tide. Alternatively, the elevation of the gates - and attached stage areas - can be individually adjusted to change the relationship between the platforms and provide dynamic event spaces.

An open plaza is incorporated into the landscape below which leads to the floodgate thoroughfares and functions as a gathering space and viewing area. Wide steps connect the east side of the plaza to the elevated riverfront path. They invite a seated audience while simultaneously providing circulation or a space for rest. 


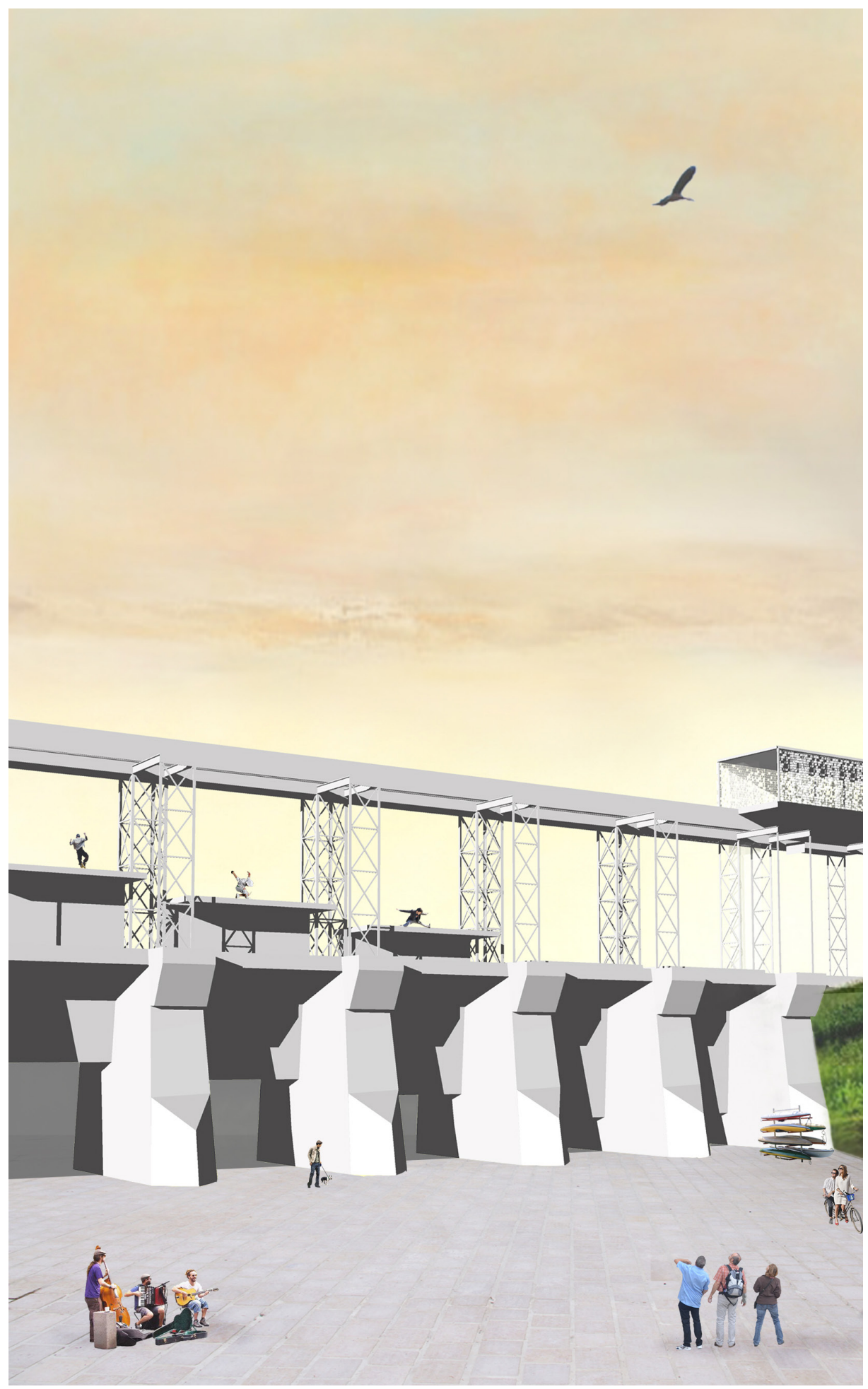

Figure 34: Proposed plaza and above stage areas 


\section{The Landscape}

So far, movement can be seen at a different scale on each level of the floodgate structure. The pedestrian thoroughfares below grade direct movement through the site on an urban scale, while the steel frame above facilitates movement within the structure itself on an architectural scale. Providing movement at a detail and sensory scale, a third architectural layer is proposed that extends above the structure and incorporates a dynamic façade.

Taking advantage of the unique view of the landscape that the height and location offers, the space provides an enclosed gathering area while acting as a viewing platform. It allows the explorer to look back at the distance covered - from whichever direction they arrived - and experience a new perspective of the ever-changing landscape.

The environmental conditions of the marshland inspire the design of the façade in an attempt to draw attention to the sensory elements that inform the place. 


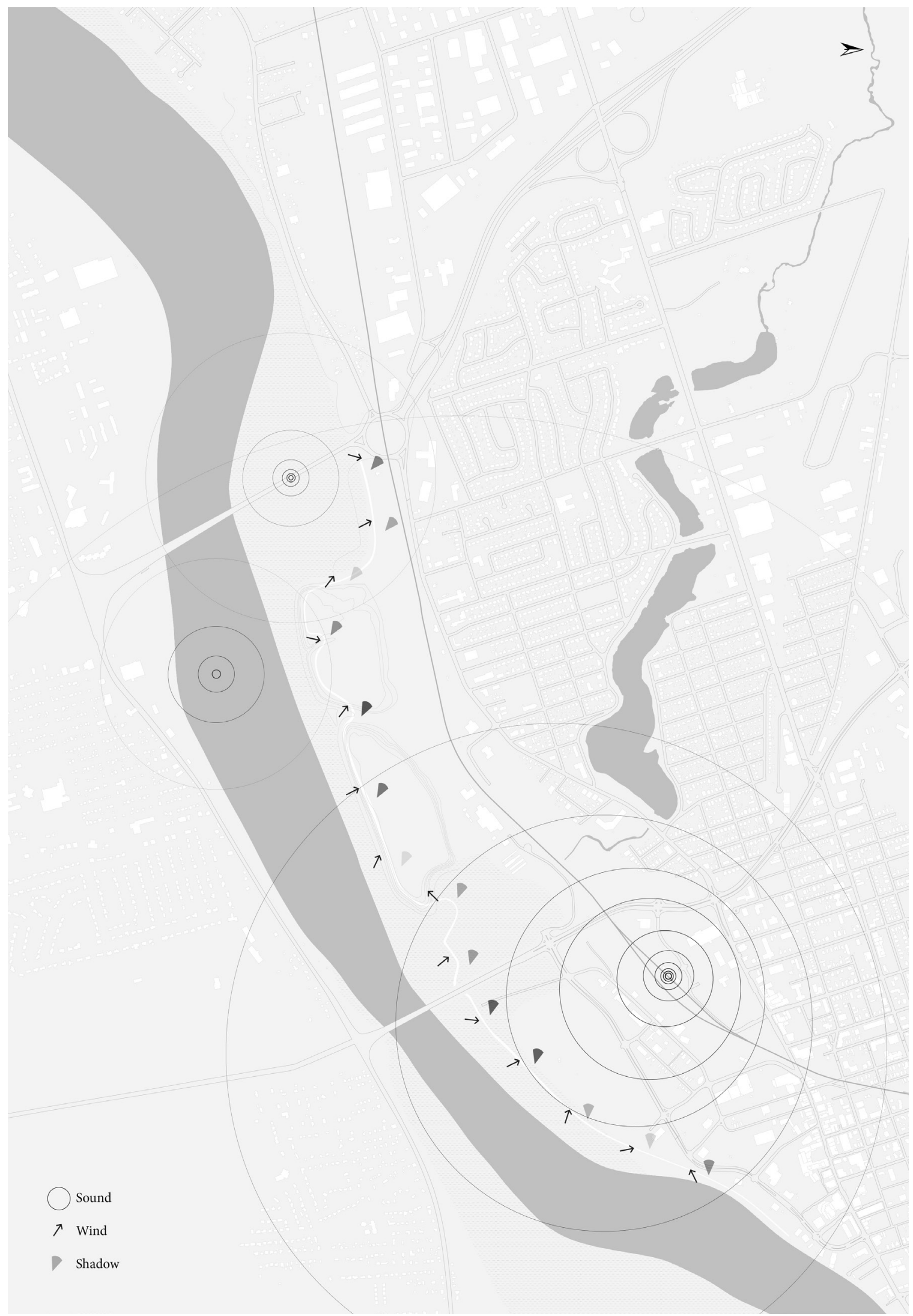

Figure 35: Site study: Diagrammatic mapping of experiential conditions during a walk through the marsh (sound, wind and shadow) 
The movement of the marsh grass as its caught by the wind and the change in the reflections on the river as the sun passes behind clouds are subtle details, yet generate strong memories of the place.

Inspired by these details of the site, the façade is composed of louvers that catch the wind, causing a fluttering effect in movement, sound, light and view. As the angle of the louvers change in response to the wind, sections of the view are consequently covered or exposed and subtle changes in light patterns occur - interiorly in daylight and exteriorly at night. The architectural experience is thus controlled by the natural elements of the site. The desired effect is to attain a calming, yet stimulating sensory environment that invites the viewer to have an engaging experience with the scenery, while appreciating the natural conditions of the site that inform its identity.

The structure is positioned so as to float over the water at high tide, while being completely exposed to the riverbank at low tide, allowing the dynamic site to be appreciated in its different forms.

The calming environment of the viewing area coupled with the length of the structure invites not only cultural gathering and events, but also artistic program; such as art, writing, or yoga classes as well as performances. Acting as a floating lightbox at night, subtly changing pattern with the wind, the architecture draws the attention of the community and serves as a beacon in the landscape. 


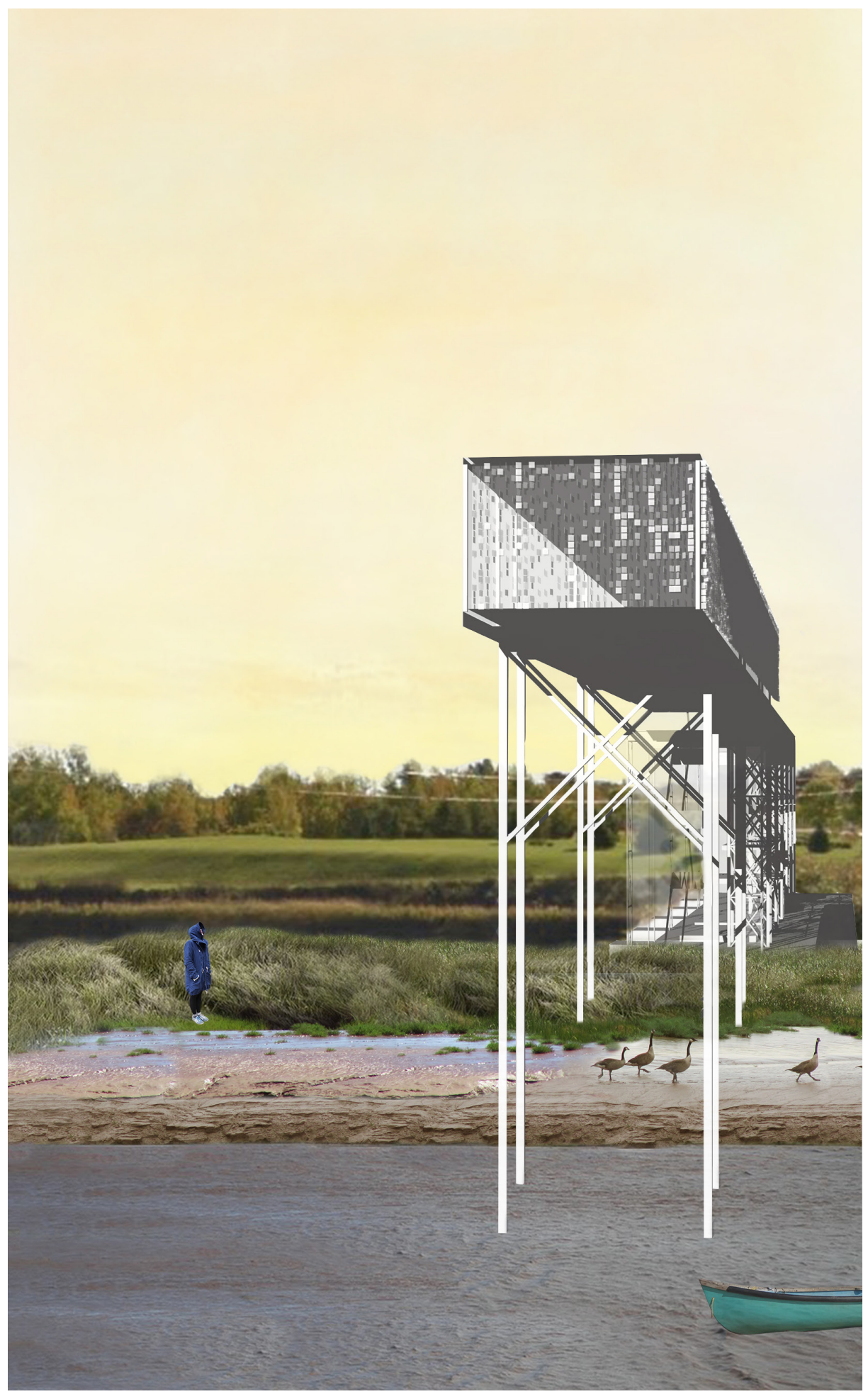

Figure 36: Proposed viewing area extending from floodgates with Riverview in the background 


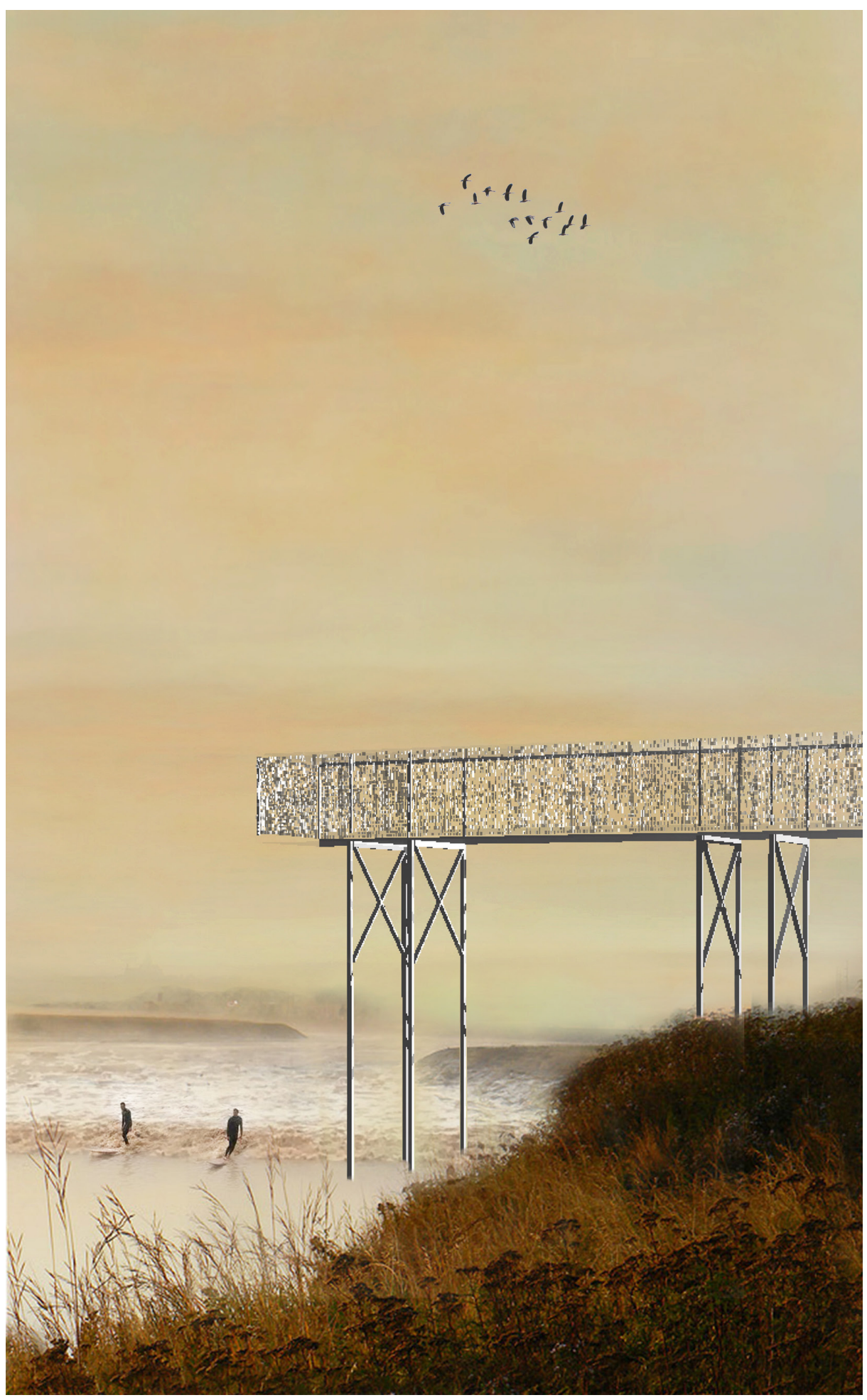

Figure 37: Proposed viewing area at tidal bore 


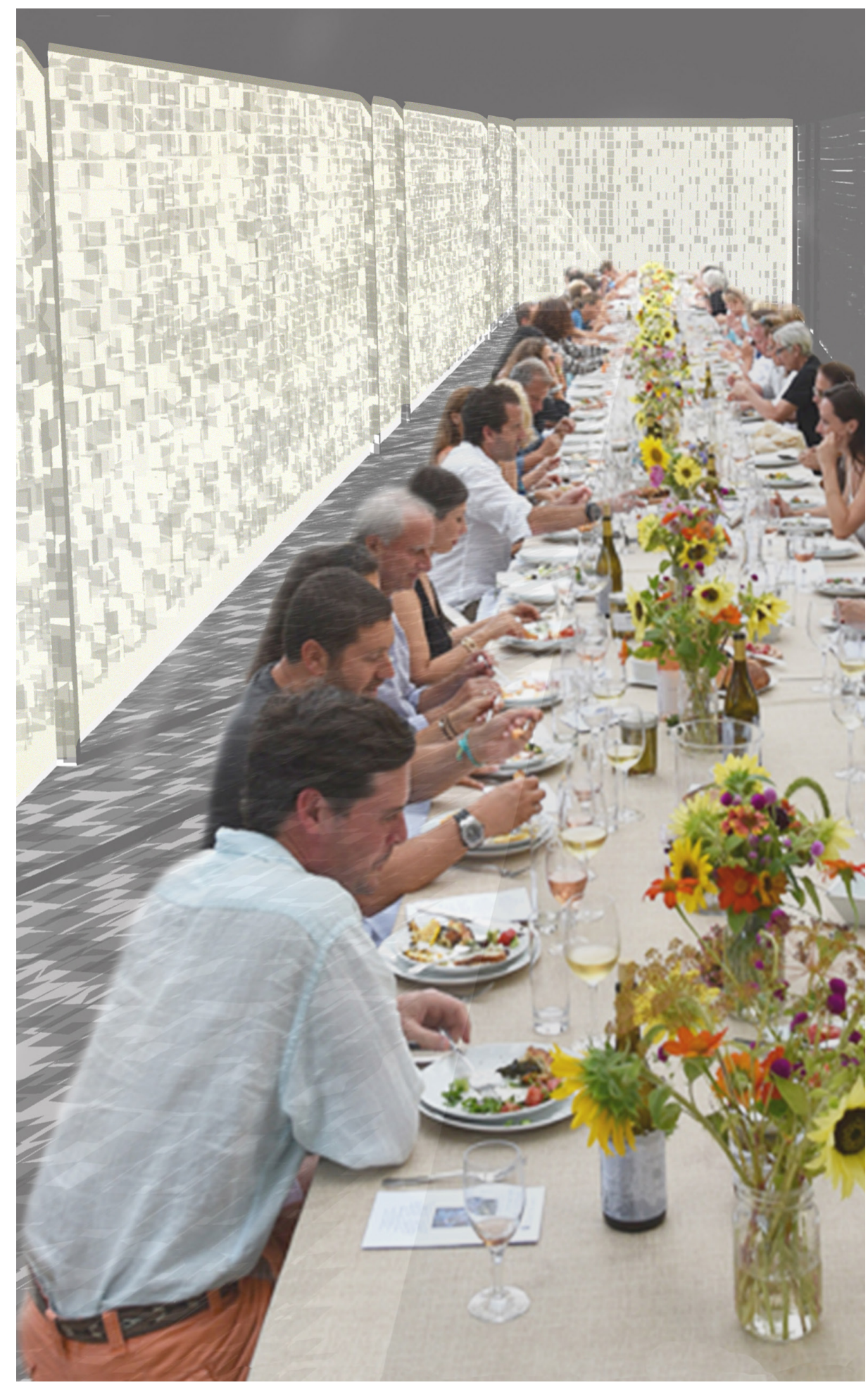

Figure 33: Interior of viewing area 


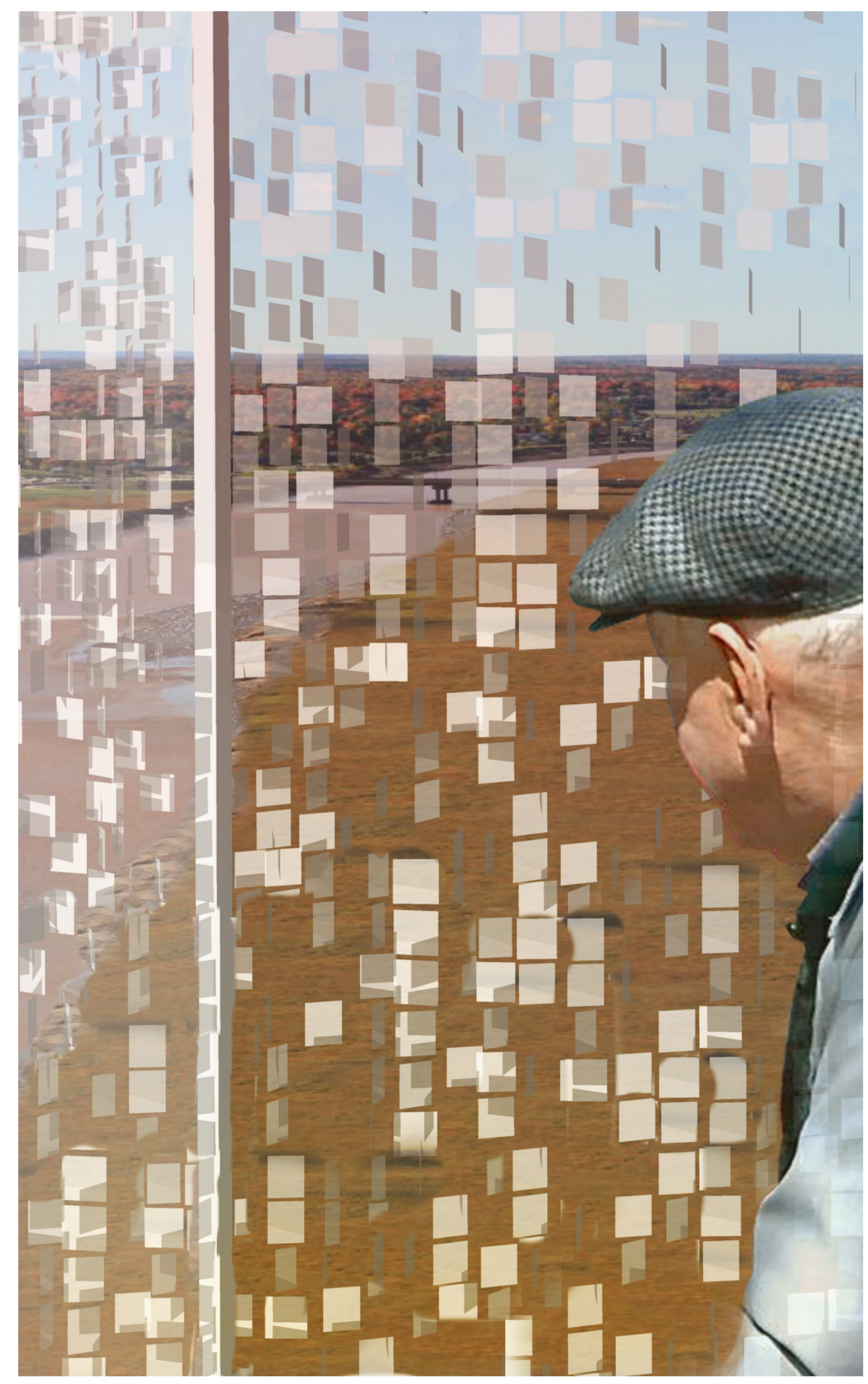

Figure 39: Looking out onto the landscape from inside the viewing area 


\section{Design Drawings}

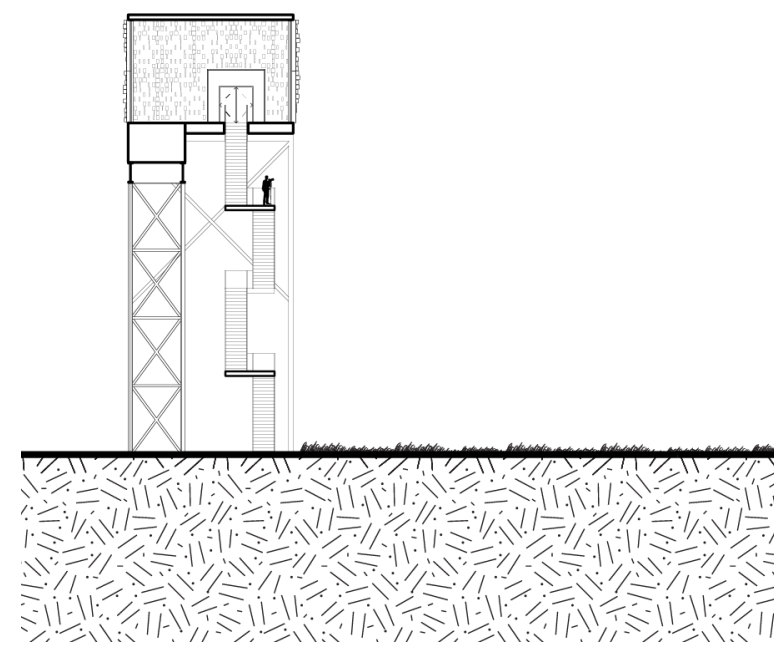

Figure 40: Preview of viewing area cross section 


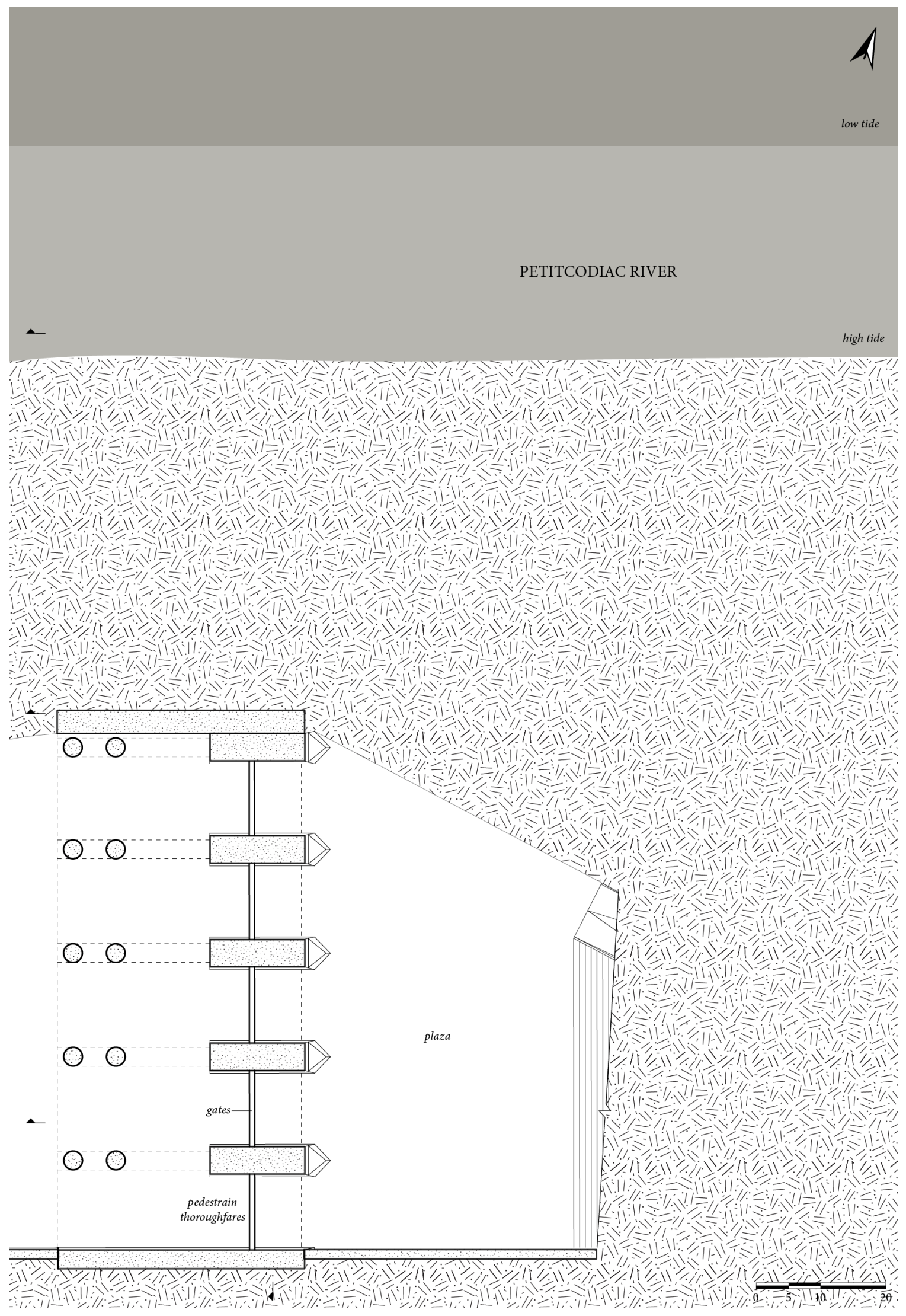

Figure 41: Plan of plaza and pedestrian thoroughfares; below grade level 


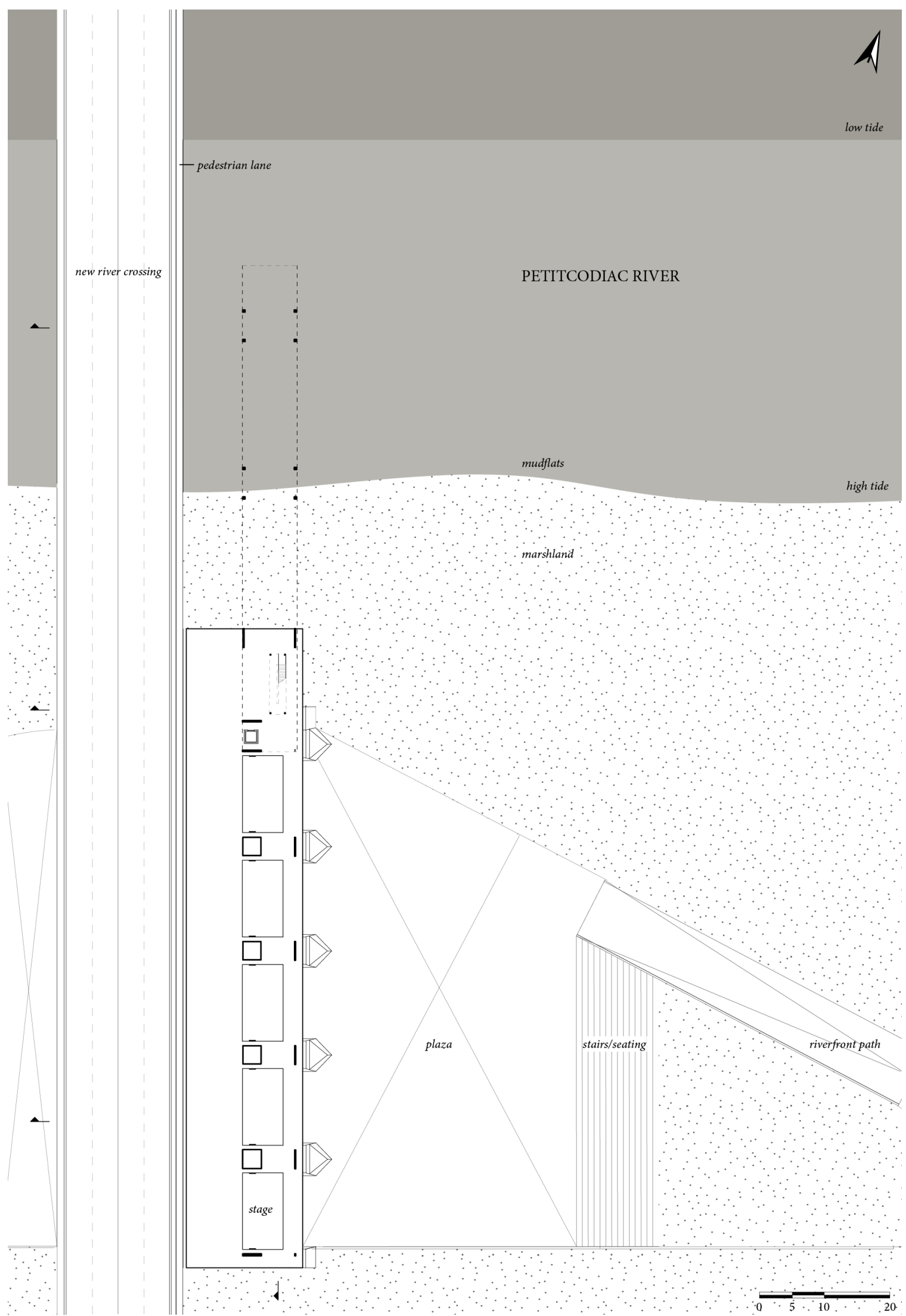

Figure 42: Plan of stage area; grade level 


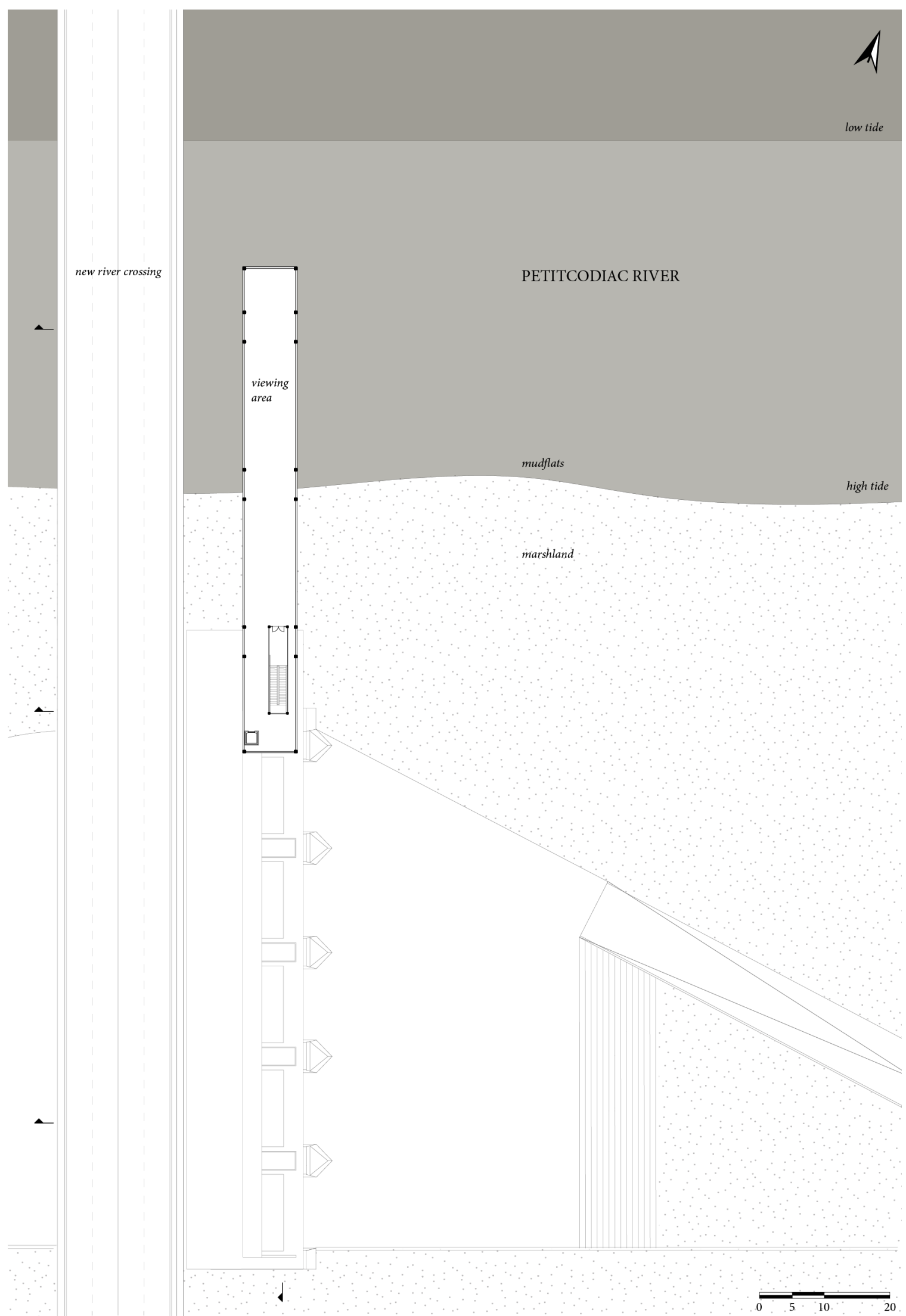

Figure 43: Plan of viewing area; level 2 


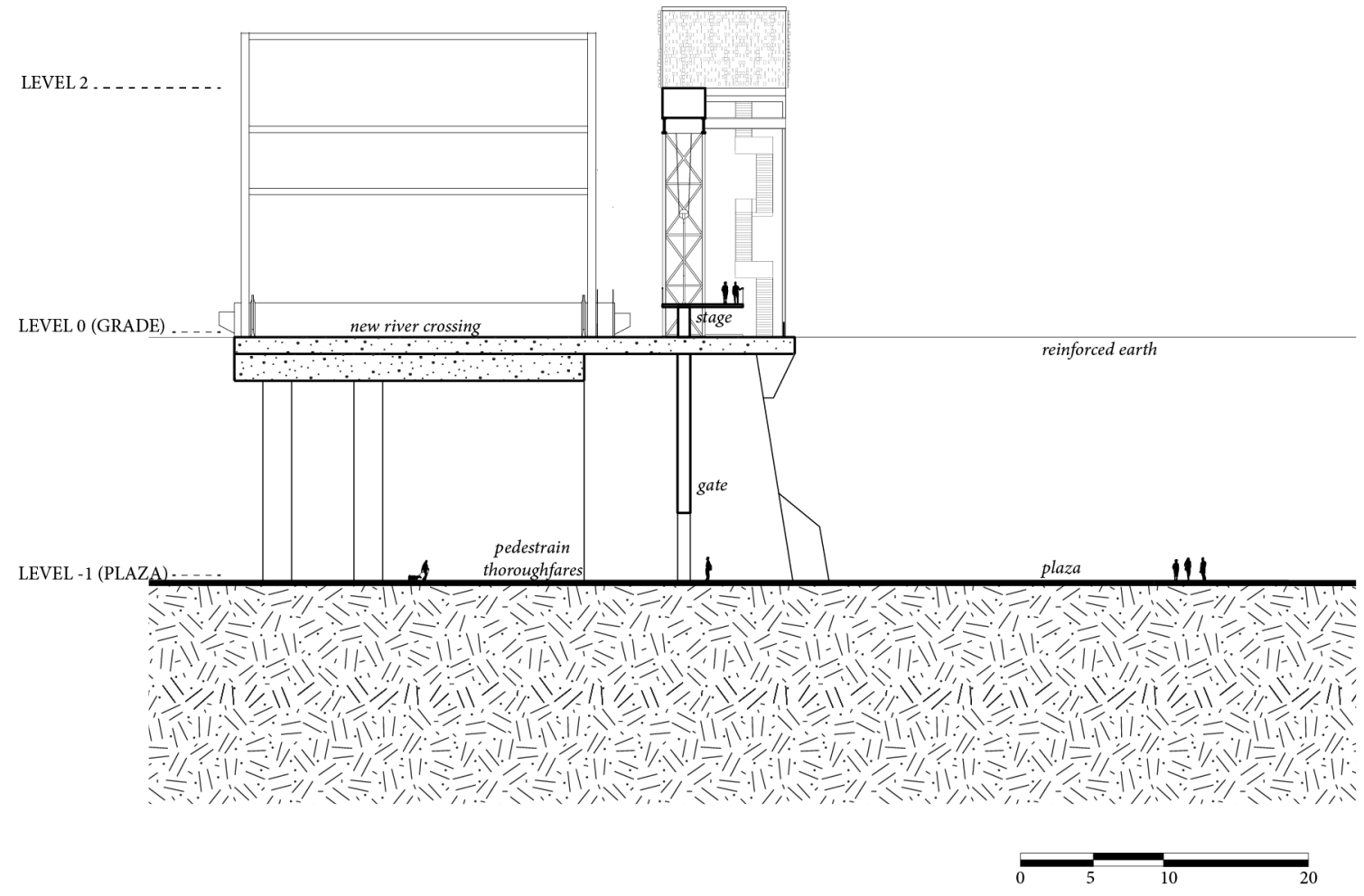

Figure 44: Cross section 1 


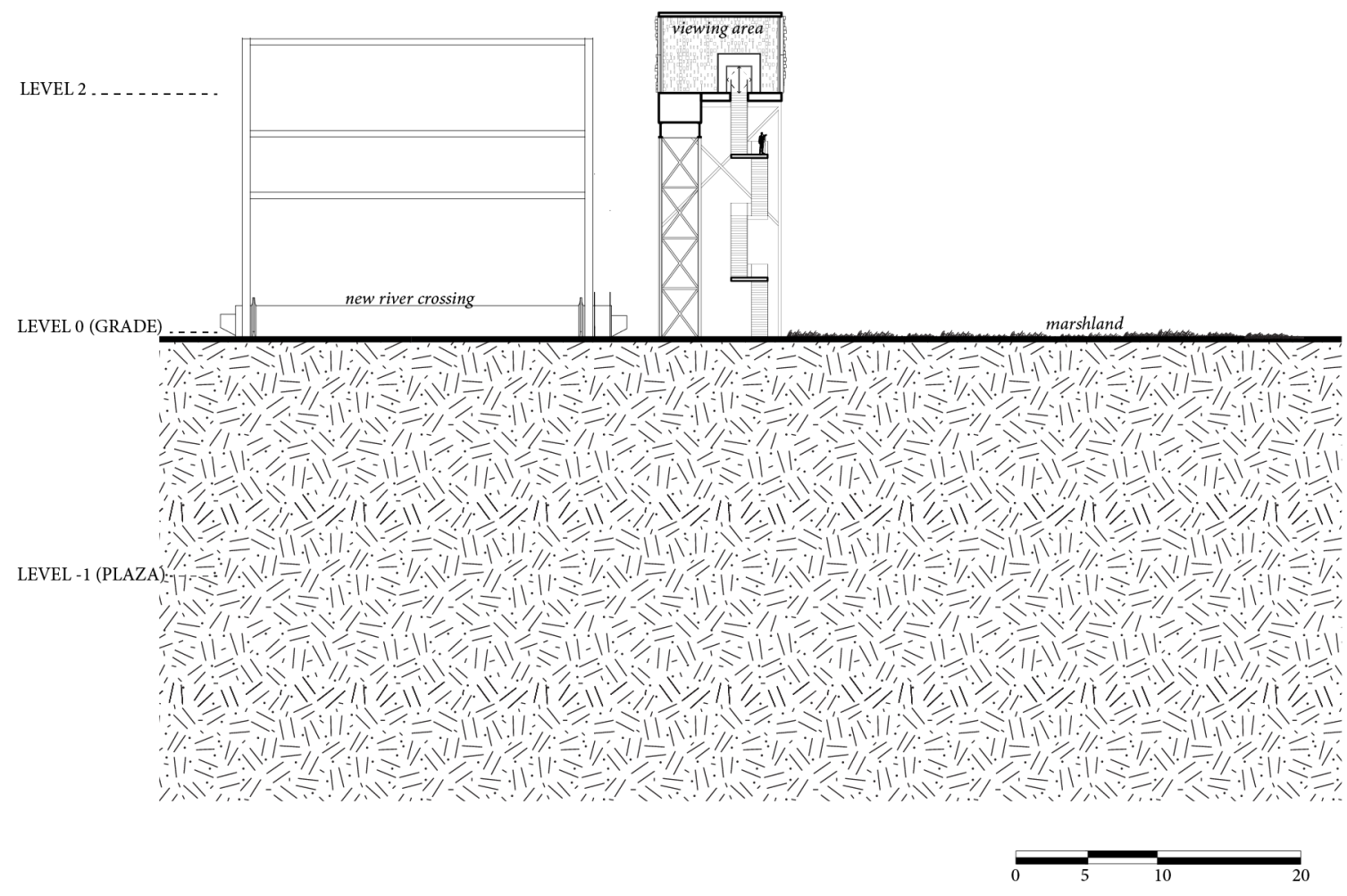

Figure 45: Cross section 2 


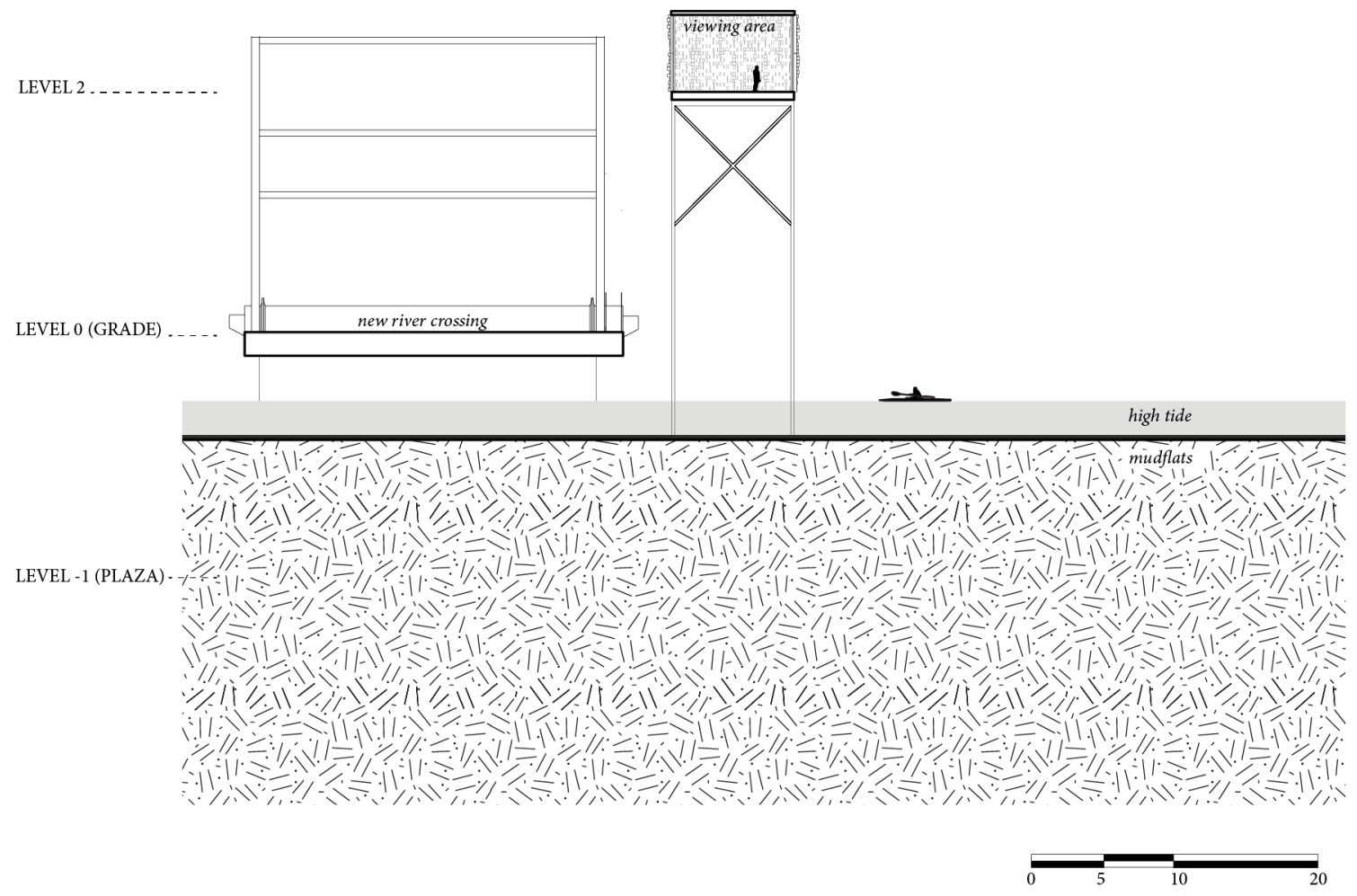

Figure 46: Cross section 3 


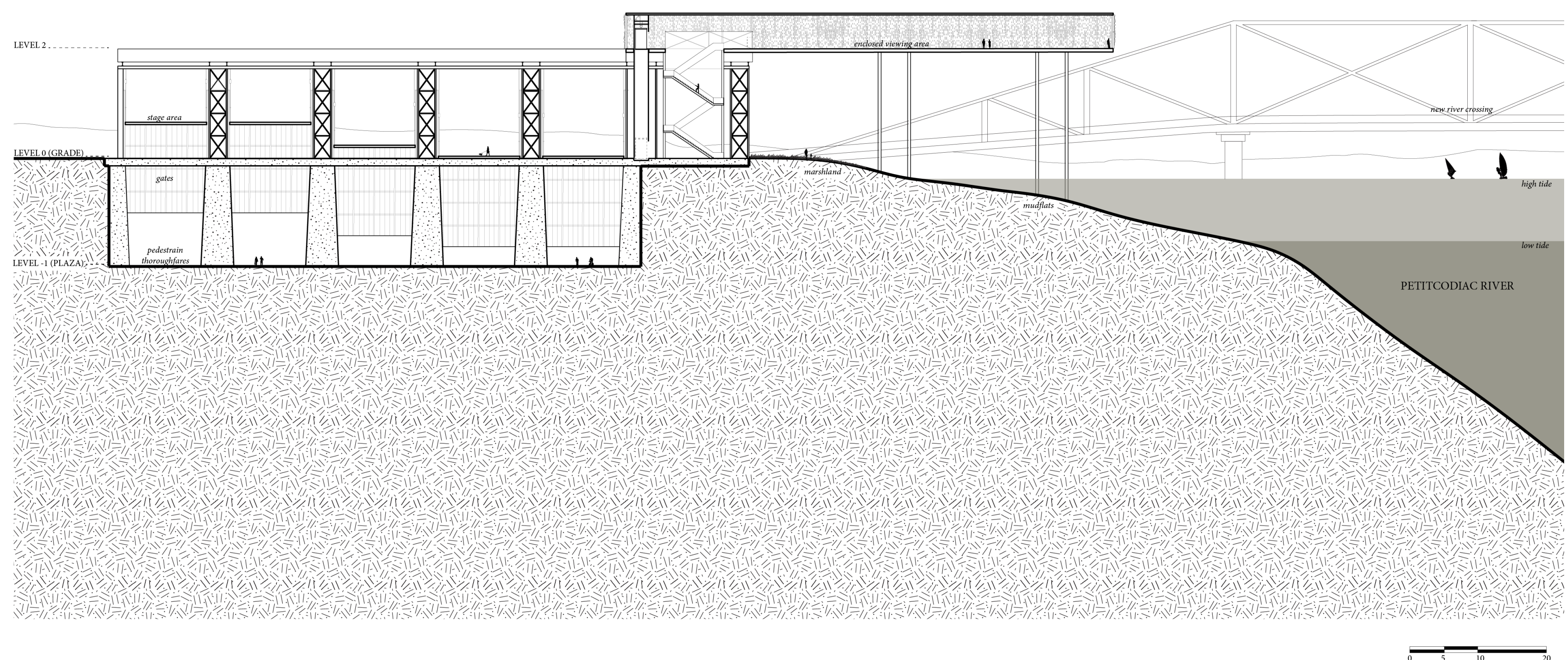




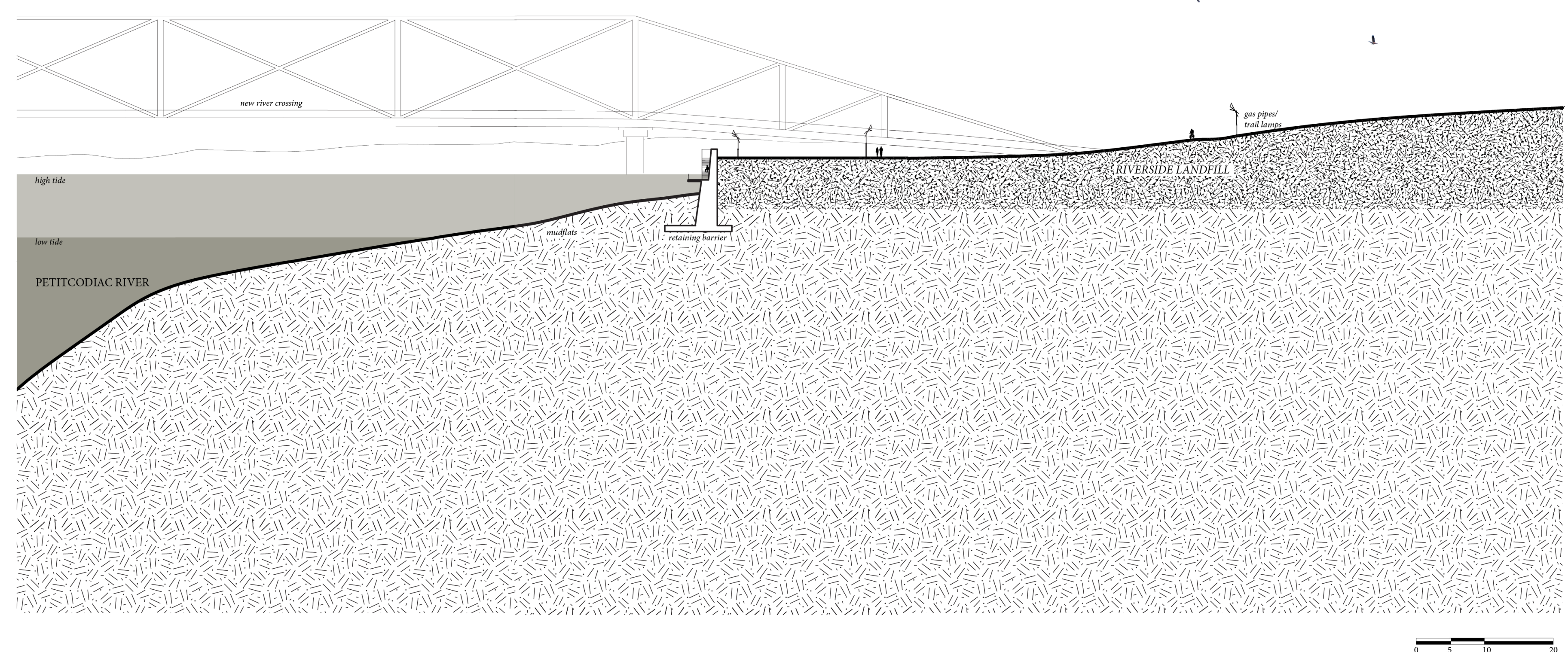

Figure 48: Longitudinal section of landfill: North side of river 


\section{CONCLUSION}

This thesis began by recognizing the identifying elements of Moncton, New Brunswick in an effort to understand the place, and realizing the importance of the river as an anchor to the city. Building on the current project to remove the causeway, the river and surrounding landscape is examined in cultural, historical, and geographical terms.

The design project demonstrates how preserving the infrastructure that once shaped the landscape can help increase a connection to both the city's history and its current conditions, while acting as an outdoor stage for cultural events. Additionally, the architecture explores methods of drawing awareness to the unique conditions of the site through an enclosed adjacent structure, while also providing a greater perspective on the site and the interventions it has seen through time.

Furthermore, the environmental concerns that arise with the removal of the causeway due to the Riverside Landfill could not be ignored. The hope is that the future causeway project can carefully manage the potential risks and thoughtfully plan prior to inviting the tidal river back through the area, and that the memories of the site will not be lost. 


\section{APPENDIX: Pet-Kout-Koy-ek}

In the beginning was the Great Spirit, who created everything in the sky, in the ocean and on the earth. He created the first man, whose name was Glooscap. And he created Pet-Kout-Koy-ek, the River That Bends Like a Bow.

Today the water of Pet-Kout-Koy-ek is brown like chocolate. But in ancient times it was clear and fresh. One day a monster Eel swam down the river, pushing all the fish and fresh water into the salty bay.

Turtle told Glooscap about the wicked Eel's misdeeds and the harm he had inflicted upon the river and its creatures. So Glooscap gave great powers to Lobster, who grew gigantic and strong enough to fight the Eel.

Their battle stirred up the mud of Pet-Kout-Koy-ek, turning the water brown, and sent waves far up the river. They fought long and hard, until Lobster prevailed and Eel was killed.

Even today, however, the battle takes place twice a day on the river now called the Petitcodiac. The wave, which forms as Lobster pushes Eel back inland, is known to most as the tidal bore.

-Derived from a Mi'kmaq legend 


\section{LIST OF ILLUSTRATIONS}

Figure 1: photo by author

Figure 2: photo by author

Figure 3: photo found at downtownmoncton.com; author unknown

Figure 4: photo by author

Figure 5: photo by Brian Branch

Figure 6: illustration by author

Figure 7: illustration by Petitcodiac Riverkeeper; edited by author

Figure 8: illustration by author

Figure 9: author unknown

Figure 10: author unknown

Figure 11: illustration by Petitcodiac Riverkeeper

Figure 12: photo found at vintagemoncton.com; author unknown

Figure 13: photo found at vintagemoncton.com; author unknown

Figure 14: photo found at vintagemoncton.com; author unknown

Figure 15: photo by author

Figure 16: photo by author

Figure 17: photo by author

Figure 18: photo found at vintagemoncton.com; author unknown

Figure 19: author unknown

Figure 20: photo by Brion Robinson/ Global News

Figure 21: author unknown

Figure 22: photo by author

Figure 23: illustration by author

Figure 24: illustration by author

Figure 25: illustration by author

Figure 26: illustration by author

Figure 27: illustration by author

Figure 28: photo by author

Figure 29: illustration by author 
Figure 30: author unknown

Figure 31: illustration by author

Figure 32: photo by author

Figure 33: illustration by author

Figure 34: illustration by author

Figure 35: illustration by author

Figure 36: illustration by author

Figure 37: illustration by author

Figure 38: illustration by author

Figure 39: illustration by author

Figure 40: illustration by author

Figure 41: illustration by author

Figure 42: illustration by author

Figure 43: illustration by author

Figure 44: illustration by author

Figure 45: illustration by author

Figure 46: illustration by author

Figure 47: illustration by author

Figure 48: illustration by author 


\section{REFERENCES}

Bachelard, Gaston. The Poetics of Space. (Boston, Beacon Press, 1969).

Bandyopadhyay, Soumyen, and Guillermo Garma Montiel. The Territories of Identity: Architecture in the Age of Evolving Globalisation. (New York, Routledge, 2013).

Blacksell, Mark. "Hoskins, W. G. 1955: The Making of the English Landscape", Progress in Human Geography, vol. 29/no. 1, (2005).

Bohme, Gernot. “Atmosphere as Mindful Physical Presence in Space." OASE vol.91 (2014), 21-32.

CBC News. Petitcodiac River Bridge Construction begins in Spring. (Accessed March 30, 2017). http://www. cbc.ca/news/canada/new-brunswick/petitcodiac-river-bridge-annoucement-daniel-leblanc-1.3899651

Endell, August, and Zeynep Çelik Alexander. “The beauty of the metropolis." Grey Room (2014) 116-38.

Fromm, Erich. To have Or to be?, Volume 50 (1st edn, New York, Harper \& Row, 1976).

Halbwachs, Maurice. The Collective Memory, Volume CN 800 (1st edn. New York, Harper \& Row, 1980).

Hashemnezhad, Hashem, Ali Akbar Heidari, and Parisa Mohammad Hoseini. "“'Sense of Place" and "Place Attachment" (A Comparative Study)", Journal of Architecture and Urban Development, vol. 3/no. 1, (2013).

Leroux, John, Stuart A. Smith, Robert Leavitt, Gary K. Hughes, Laurel Boone, and Beaverbrook Art Gallery. Building New Brunswick: An architectural history. (Fredericton, Goose Lane, 2008).

Najafi, Mina, and Mustafa Kamal Bin Mohd Shariff. "The Concept of Place and Sense of Place in Architectural Studies", World Academy of Science, Engineering and Technology International Journal of Social, Behavioral, Educational, Economic, Business and Industrial Engineering, vol. 5/no. 8, (2011).

Manzo, Lynne C. "Beyond house and haven: Toward a revisioning of emotional relationships with places." Journal of Environmental Psychology, vol 23/no.1, (2003) 47ᄀ-61.

Mohammad, Nik Mastura, Masran Saruwono, Shahrul Yani Said, and Hariri, Wan Ahmad Halawah Wan. "A sense of place within the landscape in cultural settings." Procedia - Social and Behavioral Sciences vol.105 (2013), 506-512. 
Murphy, Michael D. Landscape Architecture Theory: An Evolving Body of Thought. (Waveland, 2005).

Norberg-Schulz, Christian. Architecture: Meaning and Place, Selected Essays. (Rizzoli; First American Edition, 1988).

Pallasmaa, Juhani. The Eyes of the Skin: Architecture of the Senses. (West Sussex, Wiley, 2012).

Petitcodiac Riverkeeper. Historical Values. (Accessed March 15, 20167) http://petitcodiac.org/our-river/ historical-values/

Petitcodiac Riverkeeper. Petitcodiac Causeway: Imapacts on the Ecosystem. Accessed December 16, 2016. http://petitcodiac.org/petitcodiac-causeway/impacts-on-the-ecosystem/

Petitcodiac Riverkeeper. Riverside Landfill Case. (Accessed December 16, 2016.) http://petitcodiac.org/ riverside-landfill-case/

Quantrill, Malcolm. The Environmental Memory: Man and Architecture in the Landscape of Ideas. (Schocken Books, 1987).

Relph T. "Reflections on Place and Placelessness." Environmental and Architectural Phenomenology Newsletter, vol.7/no.3 (1996).

Rossi, Aldo. The Architecture of the City. (Cambridge, Mass, 1982).

Sauer, Carl Ortwin. The Morphology of Landscape. (California, University of California Press, 1925).

Smith, Julian. Editorial No. 3: On Cultural Landscapes. (Accessed on December 14, 2016) www.willowbank. ca.

Swaffield, Simon R. Theory in Landscape Architecture: A Reader. (Philadelphia, University of Pennsylvania Press, 2002).

Tuan, Yi-Fu. “Thought and Landscape: The Eye and the Mind's Eye," in D.W. Meinig, ed., The Interpretation of Ordinary Landscapes. (New York: Oxford University Press, 1979): 89-102. 
Vali, Amirhoosein Pouriyaye and Shahriyar Nasekhiyan. "The Concept and Sense of Place in Architecture from Phenomenological Approach", Indian Journal of Fundamental and Applied Life Sciences, vol. 4, S4 (2014): 3746-3753.

Zumthor, Peter. Atmospheres. Translated by Iain Galbraith. (Basel, Birkhäuser, 2006).

Zumthor, Peter. Thinking Architecture. Translated by Maureen Oberli-Turner and Catherine Schelbert. (Basel, Birkhäuser, 2010). 